Pacific Journal of Mathematic 


\section{ON A CLASS OF CONVOLUTION TRANSFORMS}

\section{Zeev Ditzian}

\section{In this paper the convolution transform}

$$
f(x)=\int_{-\infty}^{\infty} G(x-t) \varphi(t) d t \equiv\left(G^{*} \varphi\right)(x)
$$

whose kernel $G(t)$ is the Fourier transform of $[E(i y)]^{-1}$ where $E(s)$ is defined by

$$
\begin{aligned}
& E(s)=e^{b s} \prod_{k=1}^{\infty}\left(1-s / a_{k}\right) \exp \left(s \operatorname{Re} a_{k}^{-1}\right), \\
& \operatorname{Re} b=b \text { and } \sum\left|a_{k}\right|^{-2}<\infty
\end{aligned}
$$

will be studied. An inversion theory similar to that achieved when $a_{k}$ of (1.2) are real will be obtained. The results will show that under certain rather weak conditions, an infinite subsequence $a_{k(i)}$ of $a_{k}$ can satisfy

$$
\min \left\{\left|\arg a_{k(i)}\right|,\left|\arg -a_{k\langle i}\right|\right\} \geqq \frac{\pi}{4} \text {. }
$$

Classes of transforms will be introduced that allow the occurrence of $\min \left\{\left|\arg a_{k}\right|,\left|\arg -a_{k}\right|\right\} \geqq \pi / 4$ for all $k$.

We hope this will partly answer a problem set by Dauns and Widder [1] in Remark 1, page 441.

The inversion operator $P_{m}(D)$ is defined by

$$
P_{m}(D)=\exp \left(\left(b-b_{m}\right) D\right) \prod_{k=1}^{m}\left(1-\frac{D}{a_{k}}\right) \exp \left(\left(\operatorname{Re} \frac{1}{a_{k}}\right) D\right)
$$

where $D \equiv d / d x, \exp (k D) f(x)=f(x+k)$ and $\lim _{m \rightarrow \infty} b_{m}=0$.

The inversion formula will be

$$
\lim _{i \rightarrow \infty} P_{m(i)}(D) f(x)=\varphi(x) .
$$

This inversion formula was achieved under general conditions on $\varphi(x)$ in the case $a_{k}$ were real by I. I. Hirschman and D. V. Widder in a series of papers and in their book, "The convolution transform" [7]. Hirschman and Widder [6] also found a slightly changed version of (1.4) when $\sum_{r=1}^{\infty}\left(\operatorname{Im} a_{k} / \operatorname{Re} a_{k}\right)^{2}<\infty$. A. O. Garder [5] showed that if $a_{2 k-1}=\bar{a}_{2 k}$ then arg $a_{2 k}$ can tend to 0 or $\pi$ slower than is required in [6]. Dauns and Widder [1] showed that if $a_{2 k-1}=-a_{2 k}, 0 \leqq$ $\operatorname{Re} a_{2 k-1} \in \uparrow$ and $\left|\arg a_{2 k-1}\right|<(\pi / 4)-\eta$, where $\eta$ is independent of $k$, then (1.4) can be achieved.

It will be noted that in [1] and [5] the $a_{k}$ 's were in a special order. The order of the $a_{k}$ 's, though having no influence on $E(s)$, 
may be quite important when treating (1.4) as discussed with some examples in [2] and [4].

We shall define class $A(2)$ (that will depend also on the order of the $a_{k}$ 's). The sequence $\left\{a_{k}\right\}$ belongs to class $A(2)$ if $\operatorname{Re} a_{k} \neq 0$,

$$
\begin{aligned}
& \sum_{k=1}^{\infty}\left(\operatorname{Im}\left(a_{2 k-1}^{-1}+a_{2 k}^{-1}\right)\right)^{2} /\left(\left|a_{2 k-1}\right|^{-2}+\left|a_{2 k}\right|^{-2}\right)<\infty, \\
& (1-\theta)\left(\left|a_{2 k-1}\right|^{-2}+\left|a_{2 k}\right|^{-2}\right)+4 \operatorname{Im} a_{2 k-1}^{-1} \operatorname{Im} a_{2 k}^{-1}>0
\end{aligned}
$$

for $k>k_{0}$ for some $\theta, 0<\theta<1$ where $\theta$ is independent of $k$, and

$$
\frac{\left(\operatorname{Im}\left\{\overline{\left(a_{2 k-1}^{-1}+a_{2 k}^{-1}\right)} a_{2 k-1}^{-1} a_{2 k}^{-1}\right\}\right)^{2}\left|a_{2 k-1} a_{2 k}\right|^{2}}{\left|a_{2 k-1}\right|^{2}+\left|a_{2 k}\right|^{-2}+4 \operatorname{Im} a_{2 k-1}^{-1} \operatorname{Im} a_{2 k}^{-1}}<1-\eta
$$

for $k \geqq k_{1}$ for some $\eta, 0<\eta<1$ where $\eta$ is independent of $k$.

A transform belongs to $A(2)$ if there is an order under which $\left\{a_{n}\right\} \in A(2)$. Class $A(2)$ includes the transforms of [1], [5] and [6].

Lemma 1.1. $\sum_{k=1}^{\infty}\left(\operatorname{Im} a_{k} / \operatorname{Re} a_{k}\right)^{2}<\infty$ implies $\left\{a_{k}\right\} \in A(2)$ (and the order does not matter).

Proof. $\quad \sum_{k=1}^{\infty}\left(\operatorname{Im} a_{k} / \operatorname{Re} a_{k}\right)^{2}<\infty$ implies $\sum_{k=1}^{\infty}\left(\operatorname{Im} a_{k} /\left|a_{k}\right|\right)^{2}<\infty$ which implies $\sum_{k=1}^{\infty}\left(\operatorname{Im} a_{k}^{-1}\right)^{2} /\left|a_{k}\right|^{-2}<\infty$ which implies (1.5). To prove that $a_{k}$ satisfies (1.6) and (1.7) is not difficult.

REMARK. The inversion operator introduced by Hirschman and Widder [6] was slightly different from (1.4) but since

$$
\sum_{k=1}^{\infty}\left\{\left(\operatorname{Re} a_{k}\right)^{-1}-\operatorname{Re} a_{k}^{-1}\right\}=\sum_{k=1}^{\infty} \frac{\left(\operatorname{Im} a_{k}\right)^{2}}{\left|a_{k}\right|^{2} \operatorname{Re} a_{k}}<\infty,
$$

the difference is a change in $b$ and $b_{m}$ without changing $\lim _{m \rightarrow \infty} b_{m}=0$.

LEMMA 1.2. Let $a_{2 k-1}=-a_{2 k}$, let $\operatorname{Re} a_{2 k}>0$ and $\left|\arg a_{2 k}\right|<$ $(\pi / 4)-\eta_{1}$ for $k>k_{2}$, where $\eta_{1}$ satisfies $0<\eta_{1}<\pi / 4$ and $\eta_{1}$ is independent of $k$, then $\left\{a_{k}\right\} \in$ class $A(2)$.

Proof. It is easy to see that the sum in (1.5) is equal to zero and the right side of (1.7) is equal to zero. $\left|\arg a_{2 k}\right|<(\pi / 4)-\eta_{1}$ implies (1.6), with $\theta=1-2\left(\operatorname{Sin}\left((\pi / 4)-\eta_{1}\right)\right)^{2}$, for $k>k_{2}$.

This shows that the transforms treated in [1] are included in class $A(2)$.

LEMMA 1.3. Let $a_{2 k-1}=\overline{a_{2 k}}$ and let $\min \left\{\left|\arg a_{2 k}\right|,\left|\arg -a_{2 k}\right|\right\}<$ $(\pi / 4)-\eta_{2}$ for $k \geqq k_{2}$ where $\eta_{2}, 0<\eta_{2}<\pi / 4$, is independent of $k$, then $\left\{a_{k}\right\} \in A(2)$. 
Proof. It is easy to see that the sum in (1.5) and the right side of (1.7) are equal to zero. One can show that $\min \left\{\left|\arg a_{2 k}\right|\right.$, $\left.\left|\arg -a_{2 k}\right|\right\}<(\pi / 4)-\eta_{2}$ implies (1.6) with $\theta=1-2\left(\operatorname{Sin}\left((\pi / 4)-\eta_{2}\right)\right)^{2}$ for $k \geqq k_{2}$.

Lemma 1.3 shows that the transforms treated by A. O. Garder [5] belong to class $A(2)$. Some cases which do not belong to class $A(2)$ will be treated, among them will be the case when $a_{2 k-1}=-a_{2 k}$ and $\min \left\{\left|\arg a_{2 k}\right|,\left|\arg -a_{2 k}\right|\right\}=\pi / 4$ (see Remark 2, [1], p. 442) where estimates different from those achieved for class $A(2)$ will be obtained.

For the definition of $G(t)$

$$
G(t)=\frac{1}{2 \pi i} \int_{-i \infty}^{i \infty}[E(s)]^{-1} e^{s t} d t
$$

we have to assume that the integral on the right converges.

For the convergence of (1.8) we shall have to estimate $E(i y)$ and to these estimates the various classes correspond.

2. Estimates for $E_{2 m}(s)$ when $\left\{a_{k}\right\} \in$ class $A(2)$. In previous papers (see [1] and [6] for example) it was found useful and important to estimate $E_{m}(s)$ which is defined by

$$
E_{m}(s)=e^{b_{m} s} \prod_{k=m+1}^{\infty}\left(1-s / a_{k}\right) \exp \left(s \operatorname{Re} a_{k}^{-1}\right) .
$$

In order to estimate $E_{m}(s)$ we shall estimate one term first.

Lemma 2.1. Let $\left\{a_{k}\right\} \in$ class $A(2)$ then for $k \geqq K$

$$
\begin{aligned}
& \left|\left(1-i y / a_{2 k-1}\right)\left(1-i y / a_{2 k}\right)\right|^{2} \\
& \quad \geqq\left(1+\alpha y^{2} /\left|a_{2 k-1}\right|^{2}\right)\left(1+\alpha y^{2} /\left|a_{2 k}\right|^{2}\right)\left(1-\alpha^{-1}\left[\left(\operatorname { I m } \left(a_{2 k-1}^{-1}\right.\right.\right.\right. \\
& \left.\left.\left.\left.\quad+a_{2 k}^{-1}\right)\right)^{2} /\left(\left|a_{2 k-1}\right|^{-2}+\left|a_{2 k}\right|^{-2}\right)\right]\right) .
\end{aligned}
$$

where $0<\alpha<1$ and $\alpha$ is independent of $k$. ( $\alpha$ does depend on $\theta$ and $\eta$ of the definition of class $A(2)$ ).

Proof. By a simple calculation we get

$$
\begin{aligned}
I_{k} \equiv & \left|\left(1-i y / a_{2 k-1}\right)\left(1-i y / a_{2 k}\right)\right|^{2}=1+2 y \operatorname{Im}\left(a_{2 k-1}^{-1}+a_{2 k}^{-1}\right) \\
& +y^{2}\left\{\left|a_{2 k-1}\right|^{-2}+\left|a_{2 k}\right|^{-2}+4 \operatorname{Im} a_{2 k-1}^{-1} \operatorname{Im} a_{2 k}^{-1}\right\} \\
& +2 y^{3} \operatorname{Im}\left\{a_{2 k-1}^{-1} a_{2 k}^{-1}\left(a_{2 k-1}^{-1}+a_{2 k}^{-1}\right)\right\}+y^{4}\left|a_{2 k-1}\right|^{-2}\left|a_{k 2}\right|^{-2} .
\end{aligned}
$$

We assume $K \geqq k_{1}$ and therefore by (1.7) we get 
$\left(\operatorname{Im}\left\{\overline{\left(a_{2 k-1}^{-1}+a_{2 k}^{-1}\right)}\left(a_{2 k-1}^{-1} \cdot a_{2 k}^{-1}\right)\right\}\right)^{2}$

$$
\begin{aligned}
& \overline{\left.\left.\left[\left(1-\frac{\eta}{2}\right)\left(\left|a_{2 k-1}\right|^{-2}+\left|a_{2 k}\right|^{-2}+4 \operatorname{Im} a_{2 k-1}^{-1} \operatorname{Im} a_{2 k}^{-1}\right)\right] \cdot\left|\left(1-\frac{\eta}{2}\right)\right| a_{2 k-1} \cdot a_{2 k}\right|^{-2}\right]} \\
& \quad<(1-\eta) /\left(1-\eta+\frac{\eta^{2}}{4}\right)<1-\frac{\eta^{2}}{4} .
\end{aligned}
$$

It is easy to see that $y^{2}\left(A+2 B y+C y^{2}\right) \geqq 0$ whenever $A>0$, $C>0$ and $B^{2}<A C$. We substitute

$$
\begin{aligned}
& A-\left(1=\frac{\eta}{2}\right)\left\{\left|a_{2 k-1}\right|^{-2}+\left|a_{2 k}\right|^{-2}+4 \operatorname{Im} a_{2 k-1}^{-1} \operatorname{Im} a_{2 k}^{-1}\right\}, \\
& B=\operatorname{Im}\left\{\overline{\left(a_{2 k-1}^{-1}+a_{2 k}^{-1}\right)} a_{2 k-1}^{-1} a_{2 k}^{-1}\right\} \quad \text { and } \\
& C=\left(1-\frac{\eta}{2}\right)\left|a_{2 k-1} a_{2 k}\right|^{-2} \text {. }
\end{aligned}
$$

We use (1.6), (1.7) and the above calculation to show that, for $k>\max \left(k_{0}, k_{1}\right), A>0, C>0$ and $B^{2}>A C$. By omitting $y^{2}(A+$ $\left.2 B y+C y^{2}\right)$ from the right side of the equation defining $I_{k}$ we obtain

$$
\begin{aligned}
I_{k} \geqq & 1+2 y \operatorname{Im}\left(a_{2 k-1}^{-1}+a_{2 k}^{-1}\right) \\
& +\frac{\eta \theta}{2} y^{2}\left(\left|a_{2 k-1}\right|^{-2}+\left|a_{2 k}\right|^{-2}\right)+\frac{\eta y^{4}}{2}\left|a_{2 k-1} a_{2 k}\right|^{-2}
\end{aligned}
$$

by minimum consideration

$$
1+2 y \operatorname{Im}\left(a_{2 k-1}^{-1}+a_{2 k}^{-1}\right)
$$

$$
+\frac{\eta \theta}{4} y^{2}\left(\left|a_{2 k-1}\right|^{-2}+\left|a_{2 k}\right|^{-2}\right) \geqq 1-\frac{\frac{4}{\eta \theta}\left(\operatorname{Im}\left(a_{2 k-1}^{-1}+a_{2 k}^{-1}\right)\right)^{2}}{\left(\left|a_{2 k-1}\right|^{-2}+\left|a_{2 k}\right|^{-2}\right)}
$$

the last term tends to 1 for large $k$ because of (1.5). Using (2.3), (2.4) and letting the coefficients of $y^{2}$ and $y^{4}$ be smaller, we obtain (2.2) with $\alpha=\eta \theta / 4$.

Lemma 2.2. Suppose $\left\{a_{k}\right\} \in$ class $A(2)$. Then for $k>K$ there exist $A$ and $B, 0<A<B<1$ independent of $k$ (but they depend on $\eta$ and $\theta$ ) so that for any $r, r<\min \left(\left|a_{2 k-1}\right|,\left|a_{2 k}\right|\right)$, we shall have:

(a) For $|\sigma| \leqq A r$ and $|y| \leqq B r$

$$
\begin{aligned}
H_{k}(\sigma) \equiv & \left|\left(1-(\sigma+i y) / a_{2 k-1}\right)\left(1-(\sigma+i y) / a_{2 k}\right)\right|^{2} \exp \left(2 \sigma \operatorname{Re}\left(a_{2 k-1}^{-1}+a_{2 k}^{-1}\right)\right) \\
\geqq & 1-2 \alpha^{-1} \frac{\operatorname{Im}\left(a_{2 k-1}^{-1}+a_{2 k}^{-1}\right)}{\left|a_{2 k-1}\right|^{-2}+\left|a_{2 k}\right|^{-2}}-\frac{r^{2}}{4}\left(\left|a_{2 k-1}\right|^{-2}+\left|a_{2 k}\right|^{-2}\right) \\
& -4 \sigma^{2}\left(\operatorname{Re}\left(a_{2 k-1}^{-1}+a_{2 k}^{-1}\right)\right)^{2} .
\end{aligned}
$$

(b) For $|\sigma| \leqq A r$ and $|y| \geqq B r$ 


$$
\begin{aligned}
H_{k}(\sigma) \geqq & \left(1+\frac{\alpha}{4} y^{2}\left|a_{2 k-1}\right|^{-2}\right)\left(1+\frac{\alpha}{4} y^{2}\left|a_{2 k}\right|^{-2}\right) \\
& \times\left(1-\frac{2}{\alpha} \frac{\left(\operatorname{Im}\left(a_{2 k-1}^{-1}+a_{2 k}^{-1}\right)\right)^{2}}{\left|a_{2 k-1}\right|^{-2}+\left|a_{2 k}\right|^{-2}}\right),
\end{aligned}
$$

where $\alpha$ is that of Lemma 2.1.

Proof. By a simple calculation

$$
\begin{aligned}
& \left|\left(1-\frac{\sigma+i y}{a_{2 k-1}}\right)\left(1-\frac{\sigma+i y}{a_{2 k}}\right)\right|^{2}=\left|\left(1-\frac{i y}{a_{2 k-1}}\right)\left(1-\frac{i y}{a_{2 k}}\right)\right|^{2} \\
& \quad-2 \sigma \operatorname{Re}\left(a_{2 k-1}^{-1}+a_{2 k}^{-1}\right)+\left[\sigma^{2}\left(\left|a_{2 k-1}\right|^{-2}+\left|a_{2 k}\right|^{-2}+4 \operatorname{Re} a_{2 k-1}^{-1} \operatorname{Re} a_{2 k}^{-1}\right)\right. \\
& \quad+\sigma^{4}\left|a_{2 k-1} a_{2 k}\right|^{-2}+2 \sigma^{2} y^{2}\left|a_{2 k-1} a_{2 k}\right|^{-2}-4 \sigma y \operatorname{Im}\left(a_{2 k-1}^{-1} a_{2 k}^{-1}\right) \\
& \quad-2\left(\sigma^{2}+y^{2}\right) \sigma \operatorname{Re}\left\{\left(\overline{\left.a_{2 k-1}^{-1}+a_{2 k}^{-1}\right)} a_{2 k-1}^{-1} a_{2 k}^{-1}\right\}\right. \\
& \left.\quad+2 \sigma^{2} y \operatorname{Im}\left\{\overline{\left(a_{2 k-1}^{-1}+a_{2 k}^{-1}\right)} a_{2 k-1}^{-1} a_{2 k}^{-1}\right\}\right] \equiv I_{k}-2 \sigma \operatorname{Re}\left(a_{2 k-1}^{-1}+a_{2 k}^{-1}\right)+J_{k} .
\end{aligned}
$$

For the estimation of $J_{k}$ we shall recall that

$$
\left|\left(a_{2 k-1}^{-1}+a_{2 k}^{-1}\right) a_{2 k-1}^{-1} a_{2 k}^{-1}\right| \leqq 2\left(\left|a_{2 k-1}\right|^{-3}+\left|a_{2 k}\right|^{-3}\right)
$$

and

$$
\begin{aligned}
& \left|a_{2 k-1}\right|^{-2}+\left|a_{2 k}\right|^{-2}+4 \operatorname{Re} a_{2 k-1}^{-1} \operatorname{Re} a_{2 k}^{-1} \geqq-2\left|\operatorname{Re} a_{2 k-1}^{-1} \operatorname{Re} a_{2 k}^{-1}\right| \\
& \quad \geqq-\left(\left|a_{2 k-1}\right|^{-2}+\left|a_{2 k}\right|^{-2}\right) .
\end{aligned}
$$

To prove (a) assume $|\sigma| \leqq A r,|y| \leqq B r$. Using (2.5) and (2.6) and dropping positive terms we obtain for $A<B$

$$
\begin{aligned}
J_{k} \geqq & \left(-A^{2}-\mid 2 A B\right) r^{2}\left(\left|a_{2 k-1}\right|^{-2}+\left|a_{2 k}\right|^{-2}\right) \\
& +\left(-4\left(A^{2}+B^{2}\right) A-4 A^{2} B\right) r^{3}\left(\left|a_{2 k-1}\right|^{-3}+\left|a_{2 k}\right|^{-3}\right) \\
\geqq & \left(-3 B^{2}-12 B^{3}\right) r^{2}\left(\left|a_{2 k-1}\right|^{-2}+\left|a_{2 k}\right|^{-2}\right) .
\end{aligned}
$$

Choosing $A<B$ and (for instance) $B=3^{-2}$ and using Lemma 2.1 with $y=0$ we obtain

$$
\begin{aligned}
H_{k}(\sigma) \geqq & \left(1-\frac{\alpha^{-1}\left(\operatorname{Im}\left(a_{2 k-1}^{-1}+a_{2 k}^{-1}\right)\right)^{2}}{\left|a_{2 k-1}\right|^{-2}+\left|a_{2 k}\right|^{-2}}-\frac{1}{9} r^{2}\left(\left|a_{2 k-1}\right|^{-2}+\left|a_{2 k}\right|^{-2}\right)\right. \\
& \left.-2 \sigma \operatorname{Re}\left(a_{2 k-1}^{-1}+a_{2 k}^{-1}\right)\right) \exp \left(2 \sigma \operatorname{Re}\left(a_{2 k-1}^{-1}+a_{2 k}^{-1}\right)\right) \\
\geqq & 1-2 \alpha^{-1}\left(\operatorname{Im}\left(a_{2 k-1}^{-1}+a_{2 k}^{-1}\right)\right)^{2}\left[\left|a_{2 k-1}\right|^{-2}+\left|a_{2 k}\right|^{-2}\right]^{-1} \\
& -\frac{1}{4} r^{2}\left(\left|a_{2 k-1}\right|^{-2}+\left|a_{2 k}\right|^{-2}\right)-4 \sigma^{2}\left(\operatorname{Re}\left(a_{2 k-1}^{-1}+a_{2 k}^{-1}\right)\right)^{2} .
\end{aligned}
$$

(The coefficients in the above estimation are not the best but they are convenient). To prove (b) (for which we are free to choose $A, A<B)$ we recall that for $A \leqq \beta B, 0<\beta<1$ and $|\sigma|<A r$ we 
have

$$
\begin{aligned}
& \left.\mid 2 \sigma^{2} \operatorname{Re} a_{2 k-1}^{-1} \operatorname{Re} a_{2 k}^{-1}\right) \mid \leqq \beta^{2} B^{2} r^{2}\left(\left|a_{2 k-1}\right|^{-2}+\left|a_{2 k}\right|^{-2}\right), \\
& \left|2 \sigma^{2} y \operatorname{Im}\left\{\overline{\left(a_{2 k-1}^{-1}+a_{2 k}^{-1}\right)} a_{2 k-1}^{-1} \cdot a_{2 k}^{-1}\right\}\right| \\
& \leqq \sigma^{2} y^{2}\left|a_{2 k-1} a_{2 k}\right|^{-2}+2 \sigma^{2}\left(\left|a_{2 k-1}\right|^{-2}+\left|a_{2 k}\right|^{-2}\right),
\end{aligned}
$$$$
\left|2 y^{2} \sigma \operatorname{Re}\left\{\overline{\left(a_{2 k-1}^{-1}+a_{2 k}^{-1}\right)} a_{2 k-1}^{-1} a_{2 k}^{-1}\right\}\right|
$$$$
\leqq \beta y^{4}\left|a_{2 k-1} a_{2 k}\right|^{-2}+2 \beta y^{2}\left(\left|a_{2 k-1}\right|^{-2}+\left|a_{2 k}\right|^{-2}\right)
$$

and

$$
\begin{aligned}
& \left.\mid 2 \sigma^{3} \operatorname{Re} \overline{\left(a_{2 k-1}^{-1}+a_{2 k}^{-1}\right)} a_{2 k-1}^{-1} a_{2 k}^{-1}\right\} \mid \\
& \quad \leqq \sigma^{4}\left|a_{2 k-1} a_{2 k}\right|^{-2}+2 \sigma^{2}\left(\left|a_{2 k-1}\right|^{-2}+\left|a_{2 k}\right|^{-2}\right) .
\end{aligned}
$$

Choosing $\beta$ so that $5 \beta^{2}+4 \beta<\alpha / 4$ and $K$ so that

$$
\alpha^{-1}\left(\operatorname{Im}\left(\alpha_{2 k-1}^{-1}+\alpha_{2 k}^{-1}\right)\right)^{2} /\left(\left|a_{2 k-1}\right|^{-2}+\left|\alpha_{2 k}\right|^{-2}\right) \leqq \frac{1}{4}
$$

for $k \geqq K$ we obtain by the above estimations

$$
\begin{aligned}
& H_{k}(\sigma) \leqq\left(1+\frac{\alpha}{2} y^{2}\left|a_{2 k-1}\right|^{-2}\right)\left(1+\frac{\alpha}{2}\left|a_{2 k}\right|^{-2}\right)\left(1-\frac{1}{\alpha}\left(\operatorname{Im}\left(a_{2 k-1}^{-1}+a_{2 k}^{-1}\right)\right)^{2},\right. \\
& \left.\times\left[\left|a_{2 k-1}\right|^{-2}+\left|a_{2 k}\right|^{-2}\right]^{-1}-2 \sigma \operatorname{Re}\left(a_{2 k-1}^{-1}+a_{2 k}^{-1}\right)\right) \cdot \exp \left(2 \sigma \operatorname{Re}\left(a_{2 k-1}^{-1}+a_{2 k}^{-1}\right)\right) \\
& \quad \leqq\left(1+\frac{3 \alpha}{8} y^{2}\left|a_{2 k-1}\right|^{-2}\right)\left(1+\frac{3 \alpha}{8} y^{2}\left|a_{2 k}\right|^{-2}\right)\left(1-\frac{2}{\alpha}\left(\operatorname{Im}\left(a_{2 k-1}^{-1}+a_{2 k}^{-1}\right)\right)^{2},\right. \\
& \left.\times\left[\left|a_{2 k-1}\right|^{-2}+\left|a_{2 k}\right|^{-2}\right]^{-1}\right) \cdot\left(1-4 \sigma^{2}\left(\operatorname{Re}\left(a_{2 k-1}^{-1}+a_{2 k}^{-1}\right)\right)^{2}\right) .
\end{aligned}
$$

Since $\beta<\alpha \cdot 4^{-2}, \beta^{2}<\alpha \cdot 4^{-4}$ we obtain (b) easily.

Define $S_{m}$ and $S_{m}^{(l)}$ (see [7], [2] and [4]) by

$$
\begin{gathered}
S_{m}=\sum_{k=m+1}^{\infty}\left|a_{k}\right|^{-2} \\
S_{m}^{(l)}=S_{m}-\max _{k(1)<\cdots<k(l)} \sum_{i=1}^{l}\left|a_{k(i)}\right|^{-2} .
\end{gathered}
$$

Define also $r_{m}$ by

$$
r_{m}=\min _{k>m}\left|a_{k}\right|
$$

One can easily see that $S_{m}^{(0)}=S_{m}$ and $S_{m}^{(1)}=S_{m}-r_{m}^{-2}$.

THEOREM 2.3. Let $\left\{a_{k}\right\} \in$ class $A(2)$, then for $m \geqq K,|\sigma| \leqq A S_{2 m}^{-1 / 2}$, and $b_{2 m}=0$ we have

$$
\left|E_{2 m}(\sigma+i y)\right| \geqq \sqrt{2} / 2
$$

( $A$ being that of Lemma 2.2.) 
Proof. To prove (2.10) we use Lemma 2.2(a) whose conditions are satisfied since $S_{2 m}>r_{2 m}^{-2}, S_{2 m}^{-1 / 2}<r_{2 m}=\min _{k>2 m}\left|a_{k}\right|$. We also recall that for $A_{n}>0$ and $\sum_{n=m+1}^{\infty} A_{n}<1 / 2$ we have

$$
\prod_{n=m+1}^{\infty}\left(1-A_{n}\right) \geqq 1-\sum_{n=m+1}^{\infty} A_{n} \geqq \frac{1}{2} .
$$

Remembering that for large $m$

$$
2 \alpha^{-1} \sum_{k=m+1}^{\infty}\left(\operatorname{Im}\left(a_{2 k-1}^{-1}+a_{2 k}^{-1}\right)\right)^{2} /\left(\left|\alpha_{2 k-1}\right|^{-2}+\left|a_{2 k}\right|^{-2}\right)<\frac{1}{8}
$$

and

$$
\begin{aligned}
4 \sigma^{2} \sum_{k=m+1}^{\infty}\left(\operatorname{Re}\left(a_{2 k-1}^{-1}+a_{2 k}^{-1}\right)\right)^{2} & \leqq 8 A^{2} S_{2 m} \sum_{k=m+1}^{\infty}\left(\left|a_{2 k-1}\right|^{-2}+\left|a_{2 k}\right|^{-2}\right) \\
& \leqq 8 A^{2}<8^{-1}
\end{aligned}
$$

and using Lemma 2.2(a) we conclude the proof of (2.10) in the case where $|\sigma| \leqq S_{2 m}^{-1 / 2}$ and $|y| \leqq B S_{2 m}^{-1 / 2}$. Using Lemma 2.2(b), (2.10) in the case where $|\sigma| \leqq A S_{2 m}^{-1 / 2},|y| \geqq B S_{2 m}^{-1 / 2}$ follows by an argumentation similar to that used in the first part. Then:

THEOREM 2.4. Let $\left\{a_{k}\right\} \in A(2), b_{2 m}=0$, then for $m \geqq k,|\sigma| \leqq$ $A S_{2 m}^{-1 / 2}$ and $|y| \geqq B S_{2 m}^{-1 / 2}$ we have

$$
\begin{aligned}
\left|E_{2 m}(\sigma+i y)\right| & \geqq \frac{3}{4}\left(1+\sum_{n=1}^{\infty} \frac{1}{n !} y^{2 n} \cdot\left(\frac{\alpha}{4}\right)^{n} \cdot \prod_{l=0}^{n-1} S_{2 m}^{(l)}\right)^{1 / 2} \\
& \geqq \frac{3}{4}\left(1+\frac{1}{n !} y^{2 n}\left(\frac{\alpha}{4}\right)^{n} \prod_{l=0}^{n-1} S_{2 m}^{(l)}\right)^{1 / 2} .
\end{aligned}
$$

Proof. Using (1.5) we can choose, by the method in the proof of Theorem $2.3, \mathrm{~m}$ so that

$$
\sum_{k=m+1}^{\infty}\left(1-\frac{2}{\alpha}\left[\left(\operatorname{Im}\left(a_{2 k-1}^{-1}+a_{2 k}^{-1}\right)\right)^{2} /\left(\left|a_{2 k-1}\right|^{-2}+\left|a_{2 k}\right|^{-2}\right)\right]\right) \geqq \frac{9}{16}
$$

(9/16 can be replaced of course by any $1-\varepsilon)$.

$$
\sum_{n=1}^{\infty} \frac{1}{n !} y^{2 n}\left(\frac{\alpha}{2}\right)^{n} \prod_{l=0}^{n-1} S_{2 m}^{(l)}
$$

converges for all $y$ since $S_{2 m}=S_{2 m}^{(0)}>S_{2 m}^{(1)}>\cdots>S_{2 m}^{(l)}$. By Lemma 2.2 and (2.12) we have

$$
\left|E_{2 m}(\sigma+i y)\right| \geqq \frac{3}{4}\left(1+\sum_{n=1}^{\infty} y^{2 n}\left(\frac{\alpha}{4}\right)^{n} \sum_{\substack{k(1)>2 m \\ k(i)<k(i+1)}}\left|a_{k(1)} \cdots a_{k(n)}\right|^{-2}\right)^{1 / 2} .
$$

But we have 


$$
\begin{aligned}
I(n, m) & \equiv \sum_{\substack{2 m<k(1) \\
k(i)<k(i+1)}}\left|a_{k(1)} \cdots a_{k(n)}\right|^{-2}=\frac{1}{n !} \sum_{\substack{k(i)>2 m \\
k(i) \neq k(j), j \neq i}}\left|a_{k(1)} \cdots a_{k(n)}\right|^{-2} \\
& \geqq \frac{1}{n !} \sum_{\substack{k(i)>2 m \\
k(i) \neq k(j), j \neq i}}\left(S_{2 m}-\sum_{r=1}^{n-1}\left|a_{k(r)}\right|^{-2}\right)\left|a_{k(1)} \cdots a_{k(n-1)}\right|^{-2} \\
& \geqq \frac{1}{n !} S_{2 m}^{(n-1)} \sum_{\substack{k(2)>2 m \\
k(i) \neq k(j), j \neq i}}\left|a_{k(1)} \cdots a_{k(n-1)}\right|^{-2} \cdot
\end{aligned}
$$

Since

$$
\sum_{k(i)>2 m}\left|a_{k(i)}\right|^{-2}=S_{2 m}=S_{2 m}^{(0)},
$$

by induction $I(n, m) \geqq 1 / n ! . \prod_{l=0}^{n-1} S_{2 m}^{(l)}$, which concludes the proof of the theorem.

THEOREM 2.5. Let $\left\{a_{k}\right\} \in A(2), b_{2 m}=0$, and $\sigma$ satisfies $\operatorname{Re} a_{k} \neq \sigma$ for all $k>n$, then for $p, n=0,1,2, \cdots$ there exist $k_{1}(p, \sigma, n)$ and $k_{2}(p, \sigma, n)$ so that

$$
\left|E_{2 n}(\sigma+i \tau)\right|^{2} \geqq k_{1}(p, \sigma, n)+k_{2}(p, \sigma, n) \tau^{2 p}
$$

Proof. Since $S_{2 m}=o(1) m \rightarrow \infty$ we can choose $m$ so that $A S_{2 m}^{-1 / 2} \geqq \sigma$ (for $A$ of Theorems 2.3 and 2.4). Combining Theorems 2.3, 2.4 and the fact that $\left.\mid \prod_{k=2 n+1}^{2 m}\left(1-\sigma+i \tau / a_{k}\right)\right) e^{\sigma \operatorname{Re} a k^{-1}} \mid \geqq \delta$ whenever $\operatorname{Re} a_{k} \neq \sigma$, we obtain (2.13).

3. Estimates for $E_{m(i)}(s)$ in special cases when $\left\{a_{k}\right\} \notin A(2)$. In this section we shall estimate $E_{2 m}(s)$ in case $\left\{a_{k}\right\}$ does not necessarily belong to $A(2)$ but $a_{2 k-1}=-a_{2 k}$ or $a_{2 k-1}=\bar{a}_{2 k}$ and some other conditions are satisfied.

First we prove some lemmas concerning the above mentioned cases.

LEMмA 3.1. Let $a$ be a complex number Re $a \neq 0$, then for all real $y$ and $q \geqq 1$

$$
\begin{aligned}
I(a) & =\left|\left(1-\frac{i y}{a}\right)\left(1+\frac{i y}{a}\right)\right|^{2}=\left|\left(1-\frac{i y}{a}\right)\left(1-\frac{i y}{\bar{a}}\right)\right|^{2} \\
& \geqq\left\{\begin{array}{l}
1-q\left(\frac{\operatorname{Re} a^{2}}{|a|^{2}}\right)^{2}+\left(1-\frac{1}{q}\right) y^{4}|a|^{-4} \\
1+y^{4}|a|^{-4} \quad \text { Re } a^{2} \geqq 0 .
\end{array}\right.
\end{aligned}
$$

Proof. Simple calculation yields

$$
\begin{aligned}
& \left|\left(1-\frac{i y}{a}\right)\left(1-\frac{i y}{a}\right)\right|^{2}=1-q\left(\frac{\operatorname{Re} a^{2}}{|a|^{2}}\right)^{2} \\
& \quad+\left(\sqrt{q} \frac{\operatorname{Re} a^{2}}{|a|^{2}}+\frac{1}{\sqrt{q}} y^{2}|a|^{-2}\right)^{2}+\left(1-\frac{1}{q}\right) y^{4}|a|^{-4}
\end{aligned}
$$


from which (3.1) is immediate.

LEMMA 3.2. Let $a$ be complex number, Re $a \neq 0$, then

$$
\begin{aligned}
& \left|\left(1-\frac{\sigma+i y}{a}\right)\left(1+\frac{\sigma+i y}{a}\right)\right|^{2} \\
& =I(a)+2 \sigma^{2}\left(|a|^{2}-2(\operatorname{Re} a)^{2}|a|^{-4}\right)+\sigma^{4}|a|^{-4} \\
& \quad+2 \sigma^{2} y^{2}|a|^{-4}+4 \sigma y\left(\operatorname{Im} a^{2}\right)|a|^{-4}, \\
& \left|\left(1-\frac{\sigma+i y}{a}\right)\left(1-\frac{\sigma+i y}{\bar{a}}\right)\right|^{2} \\
& =I(a)-4 \sigma \operatorname{Re} a|a|^{-2}+\sigma^{2}\left(2|a|^{-2}+4(\operatorname{Re} a)^{2}|a|^{-4}\right) \\
& \quad+\sigma^{4}|a|^{-4}+2 \sigma^{2} y^{2}|a|^{-4}-4\left(\sigma^{2}+y^{2}\right) \sigma|a|^{-4} \operatorname{Re} a,
\end{aligned}
$$

where $I(a)$ is defined in Lemma 3.1.

Proof. The proof is a corollary of the proof of Lemma 2.2 combined with Lemma 3.1.

Lemma 3.3. Let $\operatorname{Re} a \neq 0$, then for $K>1$ there exists $A$ and $B$, independent of $a, 0<A<B<1$ such that for $r<|\operatorname{Re} a|$ we have:

(a) For $|\sigma| \leqq A r$ and $|y| \leqq B r$

$$
\begin{aligned}
& \left|\left(1-\frac{\sigma+i y}{a}\right)\left(1+\frac{\sigma+i y}{a}\right)\right|^{2} \\
& \quad \geqq 1-K^{-1} r^{2}|a|^{-2}-\left(\min \left(0,\left(\operatorname{Re} a^{2}\right) \cdot|a|^{-2}\right)\right)^{2} .
\end{aligned}
$$

(b) For $|\sigma| \leqq A r_{1} \leqq A r,|y| \geqq B r$ and $\delta>0$

$$
\begin{aligned}
\mid(1- & \left.\frac{\sigma+i y}{a}\right)\left.\left(1+\frac{\sigma+i y}{a}\right)\right|^{2} \\
\geqq & \left(1+\frac{1}{4} y^{4}|a|^{-4}\right)\left(1-2\left(\min \left(0, \operatorname{Re} a^{2} /|a|^{2}\right)\right)^{2}\right. \\
& \left.\quad-K^{-1}\left(r^{2}|a|^{-2}+r_{1}^{2}|a|^{-1-\delta}+|a|^{-2+2 \delta}\right)\right) .
\end{aligned}
$$

Proof. To prove (3.4) we use (3.2) and (3.1) with $q=1$ and obtain the result by choosing $B$ so that $6 B^{2}<K^{-1}$, and dropping some positive terms.

To prove (3.5) we use

$$
4 \sigma y\left(\operatorname{Im} a^{2}\right)|a|^{-4} \geqq-4|\sigma y||a|^{-2} \geqq-\left(\frac{1}{\beta^{2}} y^{2}|a|^{-(3-\delta)}+2 \beta^{2} \sigma^{2}|a|^{-(1+\delta)}\right)
$$




$$
-\frac{1}{\beta^{2}} y^{2}|a|^{-(3-\delta)}+\frac{1}{4} y^{4}|a|^{-4} \geqq-\frac{4}{\beta^{4}}|a|^{-(2-2 \delta)} .
$$

Choosing $4 / \beta^{4} \leqq 1 / K$ or $\beta \geqq \sqrt[4]{4 K}$ and $A$ so that $2 \beta^{2} A^{2}<K^{-1}$ or $A^{2}<1 / 4 K \sqrt{K}$ or $A<1 / 2 K$ one can conclude the proof by using Lemma 3.1 (choosing there $q=2$ in case $\operatorname{Re} a^{2}<0$ ) and dropping some positive terms.

Lemma 3.4. Let $\operatorname{Re} a \neq 0$, then for $K>1$ there exist $A$ independent of $a, 0<A<1$, such that for $r<|\operatorname{Re} a|$ and $|\sigma| \leqq A r$ we have

$$
\begin{aligned}
& \left|\left(1-\frac{\sigma+i y}{a}\right)\left(1-\frac{\sigma+i y}{\bar{a}}\right)\right|^{2} \exp \left(4 \sigma \operatorname{Re} a /|a|^{2}\right) \\
& \geqq\left(1+\frac{1}{4} y^{4}|a|^{-4}\right)\left(1-2\left(\min \left(0, \operatorname{Re} a^{2} /|a|^{2}\right)\right)^{2}-K^{-1} r^{2}|a|^{-2}\right) .
\end{aligned}
$$

Proof. Using (3.3) of Lemma 3.2, Lemma 3.1 with $q=3 / 2$, the estimations

$$
\begin{aligned}
& -4 \sigma^{3}|a|^{-4} \operatorname{Re} a \geqq-\sigma^{4}|a|^{-4}-4 \sigma^{2}(\operatorname{Re} a)^{2}|a|^{-4}, \\
& -4 y^{2} \sigma|a|^{-4} \operatorname{Re} a \geqq-\frac{1}{2^{5}} y^{4}|a|^{-4}-4^{3} \sigma^{2}|a|^{-2}
\end{aligned}
$$

and dropping some positive terms we obtain

$$
\begin{aligned}
\mid(1- & \left.\frac{\sigma+i y}{a}\right)\left.\left(1-\frac{\sigma+i y}{\bar{a}}\right)\right|^{2} \geqq 1+\left(\frac{1}{3}-\frac{1}{2^{4}}\right) y^{4}|a|^{-4} \\
& -\frac{3}{2}\left(\min \left(0, \operatorname{Re} a^{2} /|a|^{2}\right)\right)^{2}-4^{3} A^{2} r^{2}|a|^{-2}-4 \sigma(\operatorname{Re} a)|a|^{-2} .
\end{aligned}
$$

Choosing $A$ so that $4^{3} A^{2}<1 / 4 K$, which implies

$$
-4^{3} A^{2} r^{2}|a|^{-2}>-\frac{1}{4 K} r^{2}|a|^{-2}, \quad 4|\sigma||a|^{-1}<\frac{1}{4},
$$

and

$$
\exp \left(4 \sigma(\operatorname{Re} a)|a|^{-2}\right) \geqq 1+4 \sigma(\operatorname{Re} a)|a|^{-2}-4^{2} \sigma^{2}|a|^{-2}
$$

from which (3.6) follows.

We shall define now two classes of convolution transforms by the function $E(s)$ and the sequence $\left\{a_{k}\right\}$.

DeFINITION 3.1. $\left\{a_{k}\right\} \in \operatorname{class} B(2, \delta)$ if 


$$
\begin{gathered}
E(s)=\prod_{k=1}^{\infty}\left(1-s^{2} a_{k}^{-2}\right), \\
\sum_{\operatorname{Re} a_{k}^{2}<0}\left|a_{k}\right|^{-4}\left(\operatorname{Re} a_{k}^{2}\right)^{2}<\infty
\end{gathered}
$$

and

$$
\sum_{k=1}^{\infty}\left|a_{k}\right|^{-1-\delta}<\infty, \quad \sum_{k=1}^{\infty}\left|a_{k}\right|^{-2+\delta}<\infty \quad \text { for some } \delta>0 .
$$

Definition 3.2. $\left\{a_{k}\right\} \in B(2)$ if there is $\delta>0$ so that $\left\{a_{k}\right\} \in B(2, \delta)$.

DeFinition 3.3. $\left\{a_{k}\right\} \in \operatorname{class} C(2)$ if

$$
E(s)=\prod_{k=1}^{\infty}\left(1-s a_{k}^{-1}\right)\left(1-s \cdot \bar{a}_{k}^{-1}\right),
$$

if condition (3.8) is satisfied and $\sum\left|a_{k}\right|^{-2}<\infty$.

REMARK. $S_{2 m}=2 \sum_{k=m+1}^{\infty}\left|a_{k}\right|^{-2}$ in case of class $B(2)$ and $C(2)$. We have to introduce some more notations before being able to prove the estimation on $E(s)$ for transforms of classes $B(2)$ and $C(2)$.

$$
\begin{gathered}
Q_{m}=\sum_{k=m+1}^{\infty}\left|a_{k}\right|^{-4} \cdot \\
Q_{m}^{(j)}=Q_{m}-\max _{m<k(1)<\cdots<k(j)}\left\{\sum_{r=1}^{j}\left|a_{k(r)}\right|^{-4}\right\} .
\end{gathered}
$$

We shall state the estimations for classes $B(2)$ and $C(2)$ together and then outline the proofs.

THEOREM 3.5. If $\left\{a_{k}\right\} \in B(2, \delta)$, then for $m \geqq M$ and some $A$ and $B$ we have:

(a) $|\sigma| \leqq A S_{2 m}^{-1 / 2},|y| \leqq B S_{2 m}^{-1 / 2} i m p l y$

$$
\left|E_{2 m}(s)\right| \geqq 3 / 4 \text {. }
$$

(b) $|\sigma| \leqq A\left(\sum_{k=m+1}^{\infty}\left|a_{k}\right|^{-1-\delta}\right)^{-1 / 1+\delta}$ and $|y| \geqq B S_{2 m}^{-1 / 2}$ imply

$$
\left|E_{2 m}(s)\right| \geqq \frac{3}{4}\left(1+\sum_{n=1}^{\infty} \frac{1}{n !} y^{4 n} \prod_{l=0}^{n-1} Q_{m}^{(l)}\right)^{1 / 2} .
$$

THEOREM 3.6. If $\left\{a_{k}\right\} \in C(2)$ then for $m \geqq M$ there exists an $A$ so that for $|\sigma| \leqq A S_{2 m}^{-1 / 2}$ (3.14) is valid.

Proof of Theorems 3.5 and 3.6. The proof follows the proof of Theorems 2.3 and 2.4 Using Lemmas 3.3 and 3.4 we have to choose 
$r=S_{2 m}^{-1 / 2}$ and $r_{1}=\left(2 \sum_{k=m+1}^{\infty}\left|a_{k}\right|^{-1-\delta}\right)^{-1 /(1+\delta)}\left(r_{1}\right.$ necessary only in proving Theorem 3.5 from Lemma 3.3). Obviously $r_{1}<\min _{k>m}\left|a_{k}\right|, r \leqq$ $\min _{k>m}\left|a_{k}\right|$. Also we have

$$
\begin{aligned}
\sum_{k=m+1}^{\infty}\left|a_{k}\right|^{-1-\delta} \geqq\left(\sum_{k=m+1}^{\infty}\left|a_{k}\right|^{-2}\right)\left(\min _{k>m}\left|a_{k}\right|\right)^{1-\delta} \\
\geqq\left(\sum_{k=m+1}^{\infty}\left|a_{k}\right|^{-2}\right)^{(1+\delta) / 2} \cdot\left(\sum_{k=m+1}^{\infty}\left|a_{k}\right|^{-2}\right)^{(1-\delta) 1 / 2}\left(\min _{k>m}\left|a_{k}\right|\right)^{1-\delta} \\
\geqq\left(\sum_{k=m+1}^{\infty}\left|a_{k}\right|^{-2}\right)^{(1+\delta) / 2} .
\end{aligned}
$$

This implies

$$
r_{1}=\left(2 \sum_{k=m+1}^{\infty}\left|a_{k}\right|^{-1-\delta}\right)^{-1 /(1+\delta)} \leqq\left(S_{2 m}\right)^{-1 / 2} \leqq r .
$$

Choose $m$ and $K$ so that $\sum_{k>m}\left(\min \left(0, \operatorname{Re} a_{k}^{2} /\left|\alpha_{k}\right|^{2}\right)\right)^{2}<\varepsilon_{1}, 1 / K<\varepsilon_{1}(K$ of Lemmas 3.3 and 3.4) and, for proving Theorem 3.5, $\sum_{k=m+1}^{\infty}\left|a_{k}\right|^{-2+2 \delta}<\varepsilon_{1}$. The choice $\varepsilon_{1} \leqq 1 / 16$ will yield the number $3 / 4$ in (3.13) (every $1-\eta$ could be achieved by $\varepsilon_{1}$ small enough) and the coefficient $3 / 4$ in (3.14).

To complete the proof we have to show

$$
\prod_{k=m+1}^{\infty}\left(1+\frac{1}{4} y^{4}\left|a_{k}\right|^{-4}\right)=1+\sum_{n=1}^{\infty} \frac{1}{n !} y^{4 n} \prod_{l=0}^{n-1} Q_{m}^{(l)},
$$

the proof of which follows stepwise that of Theorem 2.4 .

The classes in this section are not included in $A(2)$ since (1.6) may fail to be valid. The estimates in this section are weaker in the case where the transforms are also $A(2)$.

THEOREM 3.7. Let $\left\{a_{k}\right\} \in B(2)$ or $C(2)$. Then for $\sigma$ satisfying Re $a_{k} \neq 0$ for all $k>n$, and for $p, n=0,1,2 \cdots$ there exist $k_{1}(p, \sigma, n)$ and $k_{2}(p, \sigma, n)$ such that when $\sigma \neq \operatorname{Re} a_{k}$

$$
\left|E_{2 n}(\sigma+i \tau)\right|^{2} \geqq k_{1}(p, \sigma, n)+k_{2}(p, \sigma, n) \tau^{2 p} .
$$

Proof. Deduced from Theorems 3.5 and 3.6 as Theorem 2.5 is deduced from Theorem 2.4 and 2.3.

4. Estimates for $G_{m}(t)$. We define $G_{m}(t)$, in the usual manner, by

$$
G_{m}(t)=\frac{1}{2 \pi i} \int_{-i \infty}^{i \infty}\left[E_{m}(s)\right]^{-1} e^{s t} d s, \quad G_{0}(t)=G(t) .
$$

We define also: 


$$
\begin{gathered}
\alpha(m)=\max \left\{\operatorname{Re} a_{k},-\infty \mid \operatorname{Re} a_{k}<0 \text { and } k>m\right\} . \\
\beta(m)=\min \left\{\operatorname{Re} a_{k}, \infty \mid \operatorname{Re} a_{k}>0 \text { and } k>m\right\} .
\end{gathered}
$$

We recall that in the cases $\left\{a_{k}\right\} \in A(2),\left\{a_{k}\right\} \in B(2)$ and $\left\{a_{k}\right\} \in C(2)$ we have

$$
\left|E_{2 n}(\sigma+i \tau)\right|^{2} \geqq k_{1}(p, \sigma, n)+k_{2}(p, \sigma, n) \tau^{2 p},
$$

for $n, p=0,1,2 \cdots$ and $\alpha(2 n)<\sigma<\beta(2 n)$.

THeOREM 4.1. Let $E_{n}(s), P_{n}(D)$ and $G_{n}(t)$ be defined by (2.1), (1.3) and (4.1); let (4.4) be satisfied for $m(l)$, a subsequence of $m$, then:

A. For any $\sigma$ satisfying $\sigma(m(l))<\sigma<\beta(m(l))$ we have

$$
G_{m(l)}(t)=P_{m(l)}(D) G(t)=\frac{1}{2 \pi i} \int_{\sigma-i \infty}^{\sigma+i \infty}\left[E_{m(l)}(s)\right]^{-1} e^{s t} d s .
$$

B. Suppose in case $\alpha(m(l)) \neq-\infty$ that $a_{k(1,1)}=\cdots=a_{k\left(1, m_{1}+1\right)}$, $a_{k(2,1)}=\cdots=a_{k\left(2, m_{2}+1\right)}, \cdots, a_{k(r, 1)}=\cdots=a_{k\left(r, m_{2}+1\right)}$ are all with indices greater than $m(l)$ and $\alpha(m(l))=\operatorname{Re} a_{k(1,1)}=\operatorname{Re} a_{k(2,1)}=\cdots=\operatorname{Re} a_{k(r, 1)}$, then

$$
\frac{d^{v}}{d t^{v}} G_{m(l)}(t)=\sum_{i=1}^{r} \frac{d^{v}}{d t^{v}}\left\{P_{i}(t) e^{t a k(i, 1)}\right\}+0\left(e^{k(t)}\right) \quad t \rightarrow \infty
$$

where $p_{i}(t)$ are polynomials of order $m_{i}$ and $k$ is any real number satisfying

$\max \left\{\operatorname{Re} a_{k},-\infty \mid k>m(l), \operatorname{Re} a_{k}<\alpha(m(l))\right\}<k<\alpha(m(l))$.

C. Suppose $\alpha(m(l))=-\infty$, then

$$
\frac{d^{v}}{d t^{v}} G_{m(l)}(t)=0\left(e^{k t}\right) \quad t \rightarrow \infty \text { for any real } k, k<0 \text {. }
$$

D. Suppose in case $\beta(m(l)) \neq \infty$ that $a_{r(1,1)}=\cdots=a_{r\left(1, m_{1}+1\right)}$, $\cdots a_{r(j, 1)}=\cdots=a_{r\left(j, m_{j}+1\right)}$ are all with indices greater than $m(l)$ and $\beta(m(l))=\operatorname{Re} a_{r(1,1)}=\cdots \operatorname{Re} a_{r(j, 1)}$, then

$$
\frac{d^{v}}{d t^{v}} G_{m(l)}(t)=\sum_{i=1}^{j} \frac{d^{v}}{d t^{v}}\left\{q_{i}(t) e^{t a} \boldsymbol{r ( i , 1 )}\right\}+0\left(e^{k t}\right) \quad t \rightarrow-\infty
$$

where $q_{i}(t)$ are polynomials of order $m_{i}$ and $k$ is a real number satisfying $\beta(m(l))<k<\min \left\{\operatorname{Re} \alpha_{k}, \infty \mid k>m(l), \operatorname{Re} \alpha_{k}>\beta(m(l))\right\}$.

E. Suppose $\beta(m(l))=\infty$, then

$$
\frac{d^{v}}{d t^{v}} G_{m(l)}(t)=0\left(e^{k t}\right) \quad t \rightarrow-\infty
$$


where $k$ is any real positive number.

F. For $\alpha(m(l))<\operatorname{Re} s<\beta(m(l))$ we have

$$
\frac{1}{E_{m(l)}(s)}=\int_{-\infty}^{\infty} e^{s t} G_{m(l)}(t) d t
$$

which implies

$$
1=\int_{-\infty}^{\infty} G_{m(l)}(t) d t
$$

Proof. The proof follows the method used in Hirschman and Widder's book "The convolution transform" [6, p. 108]. Formula (4.4), that was proved for class $A(2), B(2)$ and $C(2)$, is used here instead of the theorems on $E_{m}(s)$ in [6].

The following result will estimate $G_{2 m}(t)$ in the case when $m$ is large near the point $t=0$ as well as when $|t| \rightarrow \infty$.

THEOREM 4.2. Let $\left\{a_{k}\right\} \in A(2)$ and suppose that for some $n$ $S_{2 m}^{(n+1)} \geqq L_{n} S_{2 m}$ where $L_{n}>0$ is independent of $m$, then there exist $M(n)>0$ and $A>0$ such that

$$
\left|G_{2 m}^{(n)}(t)\right| \leqq M(n) S_{2 m}^{-(n+1) / 2} \exp \left(-A \cdot S_{2 m}^{-1 / 2}|t|\right) .
$$

Proof. By Theorem 4.1.A we have

$$
G_{2 m}(t)=\frac{1}{2 \pi} \int_{-\infty}^{\infty} \frac{e^{-(\sigma+i y) t}}{E_{2 m}(\sigma+i y)} d y
$$

and therefore

$$
G_{2 m}^{(n)}(t)=\frac{1}{2 \pi} \int_{-\infty}^{\infty} \frac{(\sigma+i y)^{n} e^{-(\sigma+i y) t}}{E_{2 m}(\sigma+i y)} d y .
$$

Remembering that $S_{2 m}^{(n+1)} \geqq L_{n} S_{2 m}$ implies $S_{2 m}^{(k)} \geqq L_{n} S_{2 m}$ for $k \leqq n+1$, and using Theorems 2.3 and 2.4 we obtain, choosing $\sigma=A S_{2 m}^{-1 / 2}$ for the case $t>0$,

$$
\begin{aligned}
& \left|G_{2 m}^{(n)}(t)\right| \leqq \frac{1}{2 \pi} \exp \left(-A S_{2 m}^{-1 / 2} t\right)\left\{\int_{-B S_{2 m}^{-1 / 2}}^{B S_{2 m}^{-1 / 2}} \frac{(|\sigma|+|y|)^{n}}{\left|E_{2 m}(\sigma+i y)\right|} d y\right. \\
& \left.+\int_{|y| \geqq B S_{2 m}^{-1 / 2}} \frac{(|\sigma|+|y|)^{n} d y}{\left|E_{2 m}(\sigma+i y)\right|}\right\} \leqq \exp \left(-A S_{2 m}^{-1 / 2} t\right)\left\{\frac{\sqrt{2}}{2 \pi}(A+B)^{n} 2 B S_{2 m}^{-(n+1) / 2}\right. \\
& \left.+2 \sum_{k=0}^{n}\left(\begin{array}{l}
n \\
k
\end{array}\right) S_{2 m}^{-k / 2} \frac{2}{3 \pi} \int_{B S_{2 m}^{-1 / 2}}^{\infty} \frac{y^{n-k} d y}{\left(1+y^{2(n+2)} \frac{1}{(n+2) !}\left(L_{(n)}\right)^{n+1} S_{2 m !}^{n+2}\left(\frac{\alpha}{4}\right)^{n+2}\right)^{1 / 2}}\right\} \\
& \leqq M(n) S_{2 m}^{-(n+1) / 2} \exp \left(-A S_{2 m}^{-1 / 2} t\right) .
\end{aligned}
$$


The result for $t<0$ is achieved choosing $\sigma=-A S_{2 m}^{-1 / 2}$.

REMARK. When $a_{2 k-1}=-a_{2 k}$ we have $S_{2 m}^{(1)} \geqq(1 / 2) S_{2 m}$ and therefore Theorem 4.2 for $n=0$ includes Lemma 2.4 of [1, p. 432]. Whenever the connection between pair is $0<\theta_{1} \leqq\left|a_{2 k-1} / a_{2 k}\right| \leqq \theta_{2}<\infty$, where $\theta_{1}, \theta_{2}$ are fixed for all $m$, we have $S_{2 m}^{(1)} \geqq L_{1} S_{2 m} L_{1}>0$. But in case of $n=0$ the restriction $S_{2 m}^{(1)} \geqq L_{1} S_{2 m}$ is not necessary as is proved by the following.

Theorem 4.3. Let $\left\{a_{k}\right\} \in A(2)$, then for some $A>0$ we have

$$
\left|G_{2 m}(t)\right| \leqq M S_{2 m}^{-1 / 2} \exp \left(-A S_{2 m}^{-1 / 2}|t|\right) .
$$

Proof. Following the proof of Theorem 4.2 and using Theorem 2.4 we have for $t>0$ ( $t<0$ can be treated similarly)

$$
\begin{aligned}
& \left|G_{2 m}(t)\right| \leqq \exp \left(-A S_{2 m}^{-1 / 2} t\right)\left\{\frac{\sqrt{2}}{\pi} B S_{2 m}^{-1 / 2}\right. \\
& \left.\quad+\frac{4}{3 \pi} \int_{B S_{2 m}^{-1 / 2}}^{\infty} \frac{d y}{\left(1+\frac{1}{2} y^{4} S_{2 m} S_{2 m}^{(1)}\left(\frac{\alpha}{4}\right)^{2}\right)^{1 / 2}}\right\} \\
& \int_{B S_{2 m}^{-1 / 2}}^{\infty} \frac{d y}{\left(1+L y^{4} S_{2 m} S_{2 m}^{(1)}\right)^{1 / 2}}=S_{2 m}^{-1 / 2}\left(S_{2 m} / S_{2 m}^{(1)}\right)^{1 / 4} \int_{\left(B / L^{1 / 4}\right)\left(S_{2 m} / S_{2 m}^{(1)}\right) 1 / 4}^{\infty} \frac{1}{\left(1+y^{4}\right)^{1 / 2}} d y \\
& \leqq 2^{d} S_{2 m}^{-1 / 2}\left(S_{2 m} / S_{2 m}^{(1)}\right)^{1 / 4} \int_{B_{1}\left(S_{2 m} / S_{2 m}^{(1)}\right) 1 / 4}^{\infty} \frac{d y}{1+y^{2}} \\
& \leqq 2 S_{2 m}^{-1 / 2}\left(S_{2 m} / S_{2 m}^{(1)}\right)^{1 / 4} \lim _{\zeta \rightarrow \infty}\left(\operatorname{arc} t g \zeta \zeta-\operatorname{arctg} B_{1}\left(S_{2 m} / S_{2 m}^{(1)}\right)^{1 / 4}\right) \\
& \leqq 2 S_{2 m}^{-1 / 2}\left(S_{2 m} / S_{2 m}^{(1)}\right)^{1 / 4} \lim _{\zeta \rightarrow \infty} \operatorname{arctg}\left\{\frac{1-B_{1}\left(S_{2 m} / S_{2 m}^{(1)}\right)^{1 / 4} \zeta}{\zeta^{-1}+B_{1}\left(S_{2 m} / S_{2 m}^{(1)}\right)^{1 / 4}}\right\} \leqq B_{2} S_{2 m}^{-1 / 2} .
\end{aligned}
$$

From this the proof can be easily concluded.

Lemma $3.2 \mathrm{~A}$ of $[1$, p. 434$]$ is generalized by Theorem 4.2 in case $S_{2 m}^{(2)} \geqq L_{2} S_{2 m}$ for some $L_{2}$. Case $B$ is covered only in part. The following theorem generalizes Lemma 3.2B [1, p. 434].

THEOREM 4.4. Let $a_{k} \in A(2), b_{2 m}=0$ and suppose $0<\theta_{1}<\left|a_{2 k} / a_{2 k-1}\right|<$ $\theta_{2}<\infty$ where $\theta_{1}, \theta_{2}$ are independent of $k$ and $\left|\operatorname{Re} a_{k}\right| /\left|a_{k}\right|>\eta$, then for some $A_{1}>0$ and $M_{1}$ we have:

$$
\left|G_{2 m}^{\prime}(t)\right| \leqq M_{1} S_{2 m}^{-1} \exp \left(-A_{1} S_{2 m}^{-1 / 2}|t|\right) .
$$

Proof. Let us split the proof into two cases 
(a)

$$
S_{2 m}-\max _{k>m}\left(\left|a_{k-1}\right|^{-2}+\left|a_{2 k}\right|^{-2}\right) \geqq \frac{1}{K} S_{2 m}
$$

and

$$
S_{2 m}-\max _{k>m}\left(\left|a_{2 k-1}\right|^{-2}+\left|a_{2 k}\right|^{-2}\right)<\frac{1}{K} S_{2 m}
$$

In case (a) (4.13) was proved by Theorem 4.2 for any arbitrary $K$. We shall choose $K>2$. To prove $(4.13)$ in case (b) we define $k_{0}$ by

$$
\max _{k>m}\left(\left|a_{2 k-1}\right|^{-2}+\left|a_{2 k}\right|^{-2}\right)=\left|a_{2 k_{0}-1}\right|^{-2}+\left|a_{2 k_{0}}\right|^{-2} .
$$

(In case (b) the choice of $k_{0}$ is unique.) Define $g_{k_{0}}^{*}(t)$ and $G_{2 m+2}(t)$ by:

$$
g_{k_{0}}^{*}(t)=\frac{1}{2 \pi} \int_{-\infty}^{\infty}\left[\left(1-i y / a_{2 k_{0}-1}\right)\left(1-i y / a_{2 k_{0}}\right)\right]^{-1} e^{-i y t} d y .
$$

$$
G_{2 m+2}^{*}(t)=\frac{1}{2 \pi} \int_{-\infty}^{\infty}\left[\left(1-i y / a_{2 k_{0}-1}\right)\left(1-i y / a_{2 k_{0}}\right)\right]\left(E_{2 m}(i y)\right)^{-1} e^{-i y t} d y \text {. }
$$

By $[9$, p. 255] we have

$$
G_{2 m}(t)=g_{k_{0}}^{*}(t) * G_{2 m+2}^{*}(t) .
$$

One can calculate $g_{k_{0}}^{*}(t)$ :

$$
g_{k_{0}}^{*}(t)=\frac{a_{2 k_{0}-1} a_{2 k_{0}}}{a_{2 k_{0}-1}-a_{2 k_{0}}} \begin{cases}e^{a_{2 k_{0}} t} & t \geqq 0 \\ e^{a_{2 k_{0}-1^{t}}} & t<0\end{cases}
$$

when $\operatorname{Re} a_{2 k_{0}-1}>0, \operatorname{Re} a_{2 k_{0}}<0$.

$$
g_{k_{0}}^{*}(t)= \begin{cases}\frac{a_{2 k_{0}-1} a_{2 k_{0}}}{a_{2 k_{0}}-a_{2 k_{0}-1}}\left[e^{a_{2 k_{0}-1} t}-e^{a_{2 k_{0}} t}\right] & t<0 \\ 0 & t>0\end{cases}
$$

when $\operatorname{Re} a_{2 k_{0}-1}>0, \operatorname{Re} a_{2 k_{0}}>0, a_{2 k_{0}} \neq a_{2 k_{0}-1}$.

$$
g_{k_{0}}^{*}(t)= \begin{cases}-a_{2 k_{0}}^{2} t e^{a_{2 k} t} & t<0 \\ 0 & t>0\end{cases}
$$

when $a_{2 k_{0}}=a_{2 k_{0}-1}, \operatorname{Re} a_{2 k_{0}}>0$.

Either $g_{k_{0}}^{*}(t)$ or $g_{k_{0}}^{*}(-t)$ is of the above form.

$$
G_{2 m+2}^{*}\left(t-\operatorname{Re}\left(a_{2 k_{0}+1}^{-1}+a_{2 k_{0}}^{-1}\right)\right)
$$

satisfies the assumptions of Theorem 4.3 with $S_{2 m+2}^{*}=S_{2 m}-\left|a_{2 k_{0}-1}\right|^{2}$ $-\left|a_{2 k_{0}}\right|^{2}$ and therefore 


$$
\left|G_{2 m+2}^{*}(t)\right| \leqq M\left(S_{2 m+2}^{*}\right)^{1 / 2} \exp \left(-A S_{2 m+2}^{*-1 / 2}\left|t+\operatorname{Re}\left(a_{2 k_{0}+1}^{-1}+a_{2 k_{0}}^{-1}\right)\right|\right) .
$$

Integrating by parts

$$
\begin{aligned}
G_{2 m}^{\prime}(t) & =\int_{-\infty}^{\infty} g_{k_{0}}^{*}(u) \frac{d}{d t} G_{2 m+2}^{*}(t-u) d u \\
& =\left\{\int_{-\infty}^{0}+\int_{0}^{\infty}\right\}\left(\frac{d}{d u} g_{k_{0}}^{*}(u)\right) G_{2 m+2}^{*}(t-u) d u .
\end{aligned}
$$

Since

$$
\theta_{1}^{2}\left|a_{2 k_{0}-1}\right|^{2} \leqq\left|a_{2 k_{0}}\right|^{2} \text { and }\left|a_{2 k_{0}}\right|^{2} \leqq \theta_{2}^{2}\left|a_{2 k_{0}-1}\right|^{2}
$$

we have

$$
\left(\theta_{1}^{-2}+1\right)\left|a_{2 k_{0}}\right|^{-2} \geqq \frac{1}{2} S_{2 m} \quad \text { and } \quad\left(\theta_{2}^{2}+1\right)\left|a_{2 k_{0}-1}\right|^{-2} \geqq \frac{1}{2} S_{2 m} ;
$$

therefore

$$
\max \left(\left|a_{2 k_{0}}\right|,\left|a_{2 k_{0}-1}\right|\right) \leqq\left[\left(2 \theta_{1}^{-2}+2\right)^{1 / 2}+\left(2 \theta_{2}^{2}+2\right)^{1 / 2}\right] S_{2 m}^{-1 / 2}=R_{1} S_{2 m}^{-1 / 2} .
$$

By the same method $\left(\theta_{2}^{-2}+1\right)\left|a_{2 k_{0}}\right|^{-2} \leqq S_{2 m}$ and $\left(\theta_{1}^{2}+1\right)\left|a_{2 k_{0}-1}\right|^{2} \leqq S_{2 m}$, from which we deduce

$$
\begin{gathered}
\left|\operatorname{Re} a_{2 k_{0}}\right| \geqq \eta\left|a_{2 k_{0}}\right| \geqq \eta\left(\theta_{2}^{-2}+1\right)^{-1 / 2} S_{2 m}^{-1 / 2}, \\
\left|\operatorname{Re} a_{2 k_{0}-1}\right| \geqq \eta\left(\theta_{1}^{2}+1\right)^{-1 / 2} S_{2 m}^{-1 / 2}
\end{gathered}
$$

and

$$
\min \left(\left|\operatorname{Re} a_{2 k_{0}}\right|,\left|\operatorname{Re} a_{2 k_{0}-1}\right|\right) \geqq R_{2} S_{2 m}^{-1 / 2}>0
$$

where

$$
R_{2}=\eta \cdot \min \left(\left(\theta_{2}^{-2}+1\right)^{-1 / 2},\left(\theta_{1}^{2}+1\right)^{-1 / 2}\right) .
$$

One has to estimate $G_{2 m}(t)$ for different cases of $g_{k_{0}}^{*}(t)$ of which the case where $\operatorname{Re} a_{2 k_{0}}>0, \operatorname{Re} a_{2 k_{0}-1}>0$ and $a_{2 k_{0}} \neq a_{22_{-1}}$ will be done here. The other cases are similar and simpler.

$$
\frac{d g^{*}(u)}{d u}= \begin{cases}a_{2 k_{0}-1} a_{2 k_{0}} \frac{\left(a_{2 k_{n}-1} \exp \left(a_{2 k_{n}-1} u\right)-a_{2 k_{0}} \exp \left(a_{2 k_{0}} u\right)\right)}{a_{2 k_{0}}-a_{2 k_{0}-1}} & u<0 \\ 0 & u>0 .\end{cases}
$$

Let us recall from [8, p. 203] that if $f^{\prime}(t)$ is continuous and $f(t)$ is complex valued, then

$$
\frac{f(a)-f(b)}{a-b}=\lambda f^{\prime}\left(t_{1}\right)+(1-\lambda) f^{\prime}\left(t_{2}\right) \quad t_{1}, t_{2} \in(a, b) 0<\lambda<1
$$

from which it is obvious that 


$$
\frac{f\left(\zeta_{1}\right)-f\left(\zeta_{2}\right)}{\zeta_{1}-\zeta_{2}}=\lambda f^{\prime}\left(\zeta_{3}\right)+(1-\lambda) f^{\prime}\left(\zeta_{4}\right) \quad 0<\lambda<1
$$

where $\zeta_{i}=\alpha_{i} \zeta_{1}+\left(1-\alpha_{i}\right) \zeta_{2}, 0 \leqq \alpha_{i} \leqq 1$ and $i=3,4$. Substituting $f(\zeta)=\zeta e^{\zeta}, f^{\prime}(\zeta)=e^{\zeta u}+\zeta u e^{\zeta u}$, we obtain the following estimate for $(d / d u) g^{*}(u)$ when $u<0$ :

$\left|\frac{d g^{*}(u)}{d u}\right| \leqq\left|a_{2 k_{0}-1} a_{2 k_{0}}\right|\left(\exp \left(R_{k_{0}} u\right)+\max \left(\left|a_{2 k_{0}-1}\right|,\left|a_{2 k_{0}}\right|\right)|u| \exp \left(R_{k_{0}} u\right)\right)$ where $R_{k_{0}}=\min \left(\operatorname{Re} a_{2 k_{0}-1}, \operatorname{Re} a_{2 k_{0}}\right)$. Therefore we obtain

$$
\begin{aligned}
\left|G_{2 m}^{\prime}(t)\right|= & \left|a_{2 k_{0}-1} a_{2 k_{0}}\right| \int_{-\infty}^{0} \exp \left(R_{k_{0}} u\right)\left\{1+|u| \max \left(\left|a_{2 k_{0}-1}\right|,\left|a_{2 k_{0}}\right|\right)\right\} \\
& \cdot S_{2 m+2}^{*-1 / 2} \exp \left(-A S_{2 m+2}^{*-1 / 2}\left|t-u+\operatorname{Re}\left(a_{2 k_{0}-1}^{-1}+a_{2 k_{0}}^{-1}\right)\right|\right) d u .
\end{aligned}
$$

Using relations among $S_{2 m+2}^{*}, S_{2 m}, a_{2 k_{0}}$ and $a_{2 k_{0}-1}$ one obtains

$$
\exp \left(-A S_{2 m+2}^{*-1 / 2}\left|t-u+\operatorname{Re}\left(a_{2 k_{0}-1}^{-1}+a_{2 k_{0}}^{-1}\right)\right|\right) \leqq M_{2} \exp \left(-A S_{2 m+2}^{-1 / 2}|t-u|\right) \text {. }
$$

Using this and the definition of $R_{1}$ and $R_{2}$ one derives

$$
\begin{aligned}
\left|G_{2 m}^{\prime}(t)\right| \leqq & M_{2} R_{1}^{2} S_{2 m}^{-1} \int_{-\infty}^{0} \exp \left(R_{2} S_{2 m}^{-1 / 2} u\right)\left\{1+|u| R_{1} S_{2 m}^{-1 / 2}\right\} S_{2 m+2}^{*-1 / 2} \\
& \cdot \exp \left(-A S_{2 m+2}^{*-1 / 2}|t-u|\right) d u
\end{aligned}
$$

We have to distinguish two cases $t<0$ and $t \geqq 0$. Let us prove first the theorem in case $t<0$ :

$$
\begin{aligned}
\left|G_{2 m}^{\prime}(t)\right| \leqq & M_{2} R_{1}^{2} S_{2 m}^{-1} \exp \left(-A t S_{2 m+2}^{*-1 / 2}\right) \int_{-\infty}^{t}\left\{1-u R_{1} S_{2 m}^{-1 / 2}\right\} S_{2 m+2}^{*-1 / 2} \\
& \cdot \exp \left\{\left(R_{2} S_{2 m}^{-1 / 2}+A S_{2 m+2}^{*-1 / 2}\right) u\right\} d u \\
& +M_{2} R_{1}^{2} S_{2 m}^{-1} \exp \left(A t S_{2 m+2}^{*-1 / 2}\right) \int_{t}^{0}\left\{1-u R_{1} S_{2 m}^{-1 / 2}\right\} S_{2 m+2}^{*-1 / 2} \\
& \cdot \exp \left\{\left(R_{2} S_{2 m}^{-1 / 2}-A S_{2 m+2}^{*-1 / 2}\right) u\right\} d u
\end{aligned}
$$

Choosing $K$ so that $A S_{2 m+2}^{*-1 / 2}>2 R_{2} S_{2 m}^{-1 / 2}$ we have

$$
\left|G_{2 m}^{\prime}(t)\right| \leqq M_{1} S_{2 m}^{-1} \exp \left(R_{2} t S_{2 m}^{-1 / 2}\right) \text {. }
$$

For $t>0$

$$
\begin{aligned}
\left|G_{2 m}^{\prime}(t)\right| \leqq & M_{2} R_{1}^{2} S_{2 m}^{-1} \exp \left(-A t S_{2 m+2}^{*-1 / 2}\right) \cdot \int_{-\infty}^{0}\left\{1-u R_{1} S_{2 m}^{-1 / 2}\right\} \cdot S_{2 m+2}^{*-1 / 2} \\
& \cdot \exp \left\{\left(R_{2} S_{2 m}^{-1 / 2}+A S_{2 m+2}^{*-1 / 2}\right) u\right\} d u \leqq M_{1} S_{2 m}^{-1} \exp \left(-A t S_{2 m+2}^{*-1 / 2}\right) \\
& \leqq M_{1} S_{2 m}^{-1} \exp \left(-R_{2} S_{2 m}^{-1 / 2} t\right) .
\end{aligned}
$$

Estimations similar to those achieved in Theorem 4.2 for $\left\{a_{k}\right\} \in B(2, \delta)$ and $\left\{a_{k}\right\} \in C(2)$ are developed in the following theorems. 
THEOREM 4.6. Let $\left\{a_{k}\right\} \in B(2, \delta)$ and $Q_{m}^{(j)} \geqq L(j) Q_{m}$ for some $j$, then there exist $A>0$ and $M>0$ (independent of $m$ ) so that for $k \leqq 2 j$ :

$$
\left|G_{2 m}^{(k)}(t)\right| \leqq M Q_{m}^{-k / 4} \exp \left(-A\left(2 \sum_{k=m+1}^{\infty}\left|a_{k}\right|^{-1-\tilde{o}}\right)^{-1 /(1+\tilde{o})}|t|\right)
$$

THEOREM 4.7. Let $\left\{a_{k}\right\} \in C(2)$ and $Q_{m}^{(j)} \geqq L(j) Q_{m}$ for some $j$, then there exist $A>0$ and $M>0$ (independent of $m$ ) so that for $k \leqq 2 j$ :

$$
G_{2 m}^{(k)}(t) \leqq M Q_{m}^{-k / 4} \exp \left(-A S_{2 m}^{-1 / 2}|t|\right) \text {. }
$$

One can note that in case $k=0$ no condition of the form $Q_{m}^{(j)} \geqq$ $L(j) Q_{m}$ is needed.

Proof of Theorems 4.6 and 4.7. Using Theorems 3.5 and 3.6 (for Theorems 4.6 and 4.7 respectively) we obtain by Theorem 4.1

$$
\left|G_{2 m}^{(k)}(t)\right| \leqq\left|e^{-\sigma t} \int_{\sigma+i \infty}^{\sigma-i \infty} \frac{(\sigma+i y)^{k} e^{-i y t}}{E_{2 m}(\sigma+i y)} d y\right|, \quad \beta(2 m)<\sigma<\alpha(2 m) .
$$

Using the fact that $Q_{m}^{-1 / 4}<\left((1 / 2) S_{2 m}\right)^{-1 / 2}$, as $S_{m}^{2}>Q_{m}$ (which is achieved by dropping many positive terms) and recalling that

$$
S_{2 m}^{-1 / 2}<\left(2 \sum_{k=m+1}^{\infty}\left|a_{k}\right|^{-1-\hat{o}}\right)^{1 / 1+o}
$$

we obtain

$$
Q_{m}^{-1 / 4}<\left(\sum_{k=m+1}^{\infty}\left|a_{k}\right|^{-1-\delta}\right)^{1 / 1+\delta}
$$

The completion of the proof is similar to the proof of Theorem 4.2.

5. Some inversion theorems. In this section we shall show that inversion formulae can be given for $\left\{a_{k}\right\} \in A(2),\left\{a_{k}\right\} \in B(2, \delta)$ and $\left\{a_{k}\right\} \in C(2)$.

THEOREM 5.1. Suppose: (1) $G(t)$ and $E(s)$ are defined by (1.2) and $\left\{a_{k}\right\} \in A(2)$.

(2) $f(x)=\int_{-\infty}^{\infty} G(x-t) \varphi(t) d t$.

(3) For some $M$ and $K,|\varphi(t)| \leqq K e^{M|t|}$, where $M<\min \left|\operatorname{Re} a_{n}\right|$.

(4) $b_{2 m}=o(1) \quad m \uparrow \infty$.

Then

(5.1) $\quad \lim _{m \rightarrow \infty} P_{2 m}(D) f(x)=\lim _{m \rightarrow \infty} \exp \left(\left(b-b_{2 m}\right) D\right) \prod_{k=1}^{m}\left(1-\frac{D}{a_{2 k-1}}\right)\left(1-\frac{D}{a_{2 k}}\right)$. 
$\exp \left(\left(\operatorname{Re} a_{2 k-1}^{-1}+a_{2 k}^{-1}\right) D\right) f(x)=\varphi(x)$ at any point of continuity of $\varphi(t)$.

Proof. By steps following those of [1; p. 433]

$$
\begin{aligned}
& \left|P_{2 m}(D) f(x)-\varphi(x)\right| \\
& \quad \leqq \sup _{|t|<\dot{o}}|\varphi(x-t)-\varphi(x)| \int_{-\infty}^{\infty}\left|G_{2 m}(t)\right| d t+M_{0} \int_{|t|>\hat{o}}\left|G_{2 m}(t)\right| e^{M[i \mid} d t .
\end{aligned}
$$

Using Theorem 4.3, the conditions of which are satisfied by the kernel $G_{2 m}\left(t+b_{m}\right)$, choosing $m$ so big that $\left|b_{m}\right|<\delta / 2$ and $A S_{2 m}^{-1 / 2}>4 M$, we conclude the proof of the theorem.

Theorem 5.2. Suppose: Assumptions (1) and (2) of Theorem 5.1 are satisfied

(3) For $\alpha(t)=\int_{0}^{t} \varphi(u) d u$ there exist positive $M$ and $K$ so that $|\alpha(t)| \leqq k e^{M|t|}$ where $M<\operatorname{Min}\left|\operatorname{Re} a_{k}\right|$.

(4) $b_{2 m}=o\left(S_{2 m}^{1 / 2}\right) m \rightarrow \infty$.

( 5 ) $\quad \int_{0}^{h}[\varphi(x+y)-\varphi(x)] d y=o(h) h \rightarrow 0$.

(6) Either $S_{2 m}^{(2)} \geqq L(2) S_{2 m}$ or $0<\theta_{1}<\left|a_{2 k-1} / a_{2 k}\right|<\theta_{2}<\infty$ and $\mid$ Re $a_{k} /\left|a_{k}\right| \mid>\eta$.

Then $\lim _{m \rightarrow \infty} P_{2 m}(D) f(x)=\varphi(x)$.

Proof. Integrating by parts and since $\int_{-\infty}^{\infty} G_{2 m}(t) d t=1$ we obtain

$$
\begin{aligned}
& \left|P_{2 m}(D) f(x)-\varphi(x)\right| \\
& \quad>\int_{|x-t| \leqq \delta}|\beta(t)|\left|G_{2 m}^{\prime}(x-t)\right| d t+\int_{|x-t| \geqq \delta}\left|G_{2 m}^{\prime}(x-t)\right||\beta(t)| d t,
\end{aligned}
$$

where $\beta(t)=\int_{x}^{t}[\varphi(x+u)-\varphi(x)] d u$ and therefore $\beta(x+t)=o(t) t \rightarrow 0$ and $|\beta(t)| \leqq K_{1} e^{M|t|}$.

To obtain the inversion result for the case $S_{2 m}^{(2)} \geqq L(2) S_{2 m}$ we use the estimation from Theorem 4.2; while for $\left|\operatorname{Re} a_{k}\right| a_{k} \mid>\eta, 0<\theta_{1}<$ $\left|a_{2 k-1}\right| a_{2 k} \mid<\theta_{2}<\infty$ we use Theorem 4.4, both are applicable to $G_{2 m}\left(t+b_{2 m}\right)$.

REMARK 1. In case $a_{2 k-1}=-a_{2 k}$ (from some $k$ onward) we can drop (5) and write instead

$$
\int_{0}^{h}[\varphi(x \pm y)-\varphi(x \pm 0)] d y=o(h) \quad h \rightarrow 0+
$$

(if the numbers $\varphi(x \pm 0)$ exist) and then if we write $b_{2 m}=0$ instead of (4) and drop (6), we shall obtain 


$$
\lim _{m \rightarrow \infty} P_{2 m}(D) f(x)=\frac{1}{2}[\varphi(x+0)+\varphi(x-0)] .
$$

The proof is similar if we remember that $G_{2 m}(t)=G_{2 m}(-t)$ and therefore $\int_{-\infty}^{0} G_{2 m}(t) d t=1 / 2$.

REMARK 2. The condition (3) of Theorem 5.2 seems too strong since for the case where $a_{k}$ are real the assumption could be dropped. We hope that at least for some classes of $\left\{a_{k}\right\}$ Theorem 5.2 could be proved without (3).

THEOREM 5.3. Suppose: (1) $G(t)$ and $E(s)$ are defined by (1.2) and $\left\{a_{k}\right\} \in B(2, \delta)$.

(2) $f(x)=\int_{-\infty}^{\infty} G(x-t) \varphi(t) d t$.

(3) For some $M$ and $K|\varphi(t)| \leqq K e^{M|t|}$ where $M=\min \left|\operatorname{Re} a_{k}\right|$.

(4) $\left\{\left(\sum_{k=m+1}^{\infty}\left|a_{k}\right|^{-1-\delta}\right)^{1 / 1+\delta}\right\}^{\beta} \leqq K Q_{m}^{1 / 4}$ for some $\beta \geqq 1$.

(5) $\varphi(x)-\varphi(t)=0\left(|t-x|^{\beta-1}\right) t \rightarrow x$.

Then

$$
\lim _{m \rightarrow \infty} P_{2 m}(D) f(x)=\varphi(x)
$$

Proof. We have

$$
\begin{aligned}
& \left|P_{2 m}(D) f(x)-\varphi(x)\right|=\mid\left\{\int_{|x-t| \geqq \delta}+\int_{|x-t| \leqq \delta}\right\} G_{2 m}(x-t)[\varphi(t)-\varphi(x) d x \mid \\
& \quad \leqq K_{1} \int_{|t-x| \geqq \delta}\left|G_{2 m}(x-t)\right| e^{M t} d t+\varepsilon \int_{-\infty}^{\infty}\left|G_{2 m}(t)\right||t|^{\beta-1} d t \\
& \quad \leqq o(1)+\varepsilon K_{2} \int_{-\infty}^{\infty} Q_{m}^{-1 / 4}|t|^{\beta-1} \exp \left(-A\left(\sum_{k=m+1}^{\infty}\left|a_{k}\right|^{-1-\hat{\delta}}\right)^{-1 / 1+\delta}|t|\right) d t \\
& \quad \leqq o(1)+\varepsilon K_{2} K \int_{-\infty}^{\infty}|u|^{\beta-1} \exp (-A u) d u \leqq o(1)+\varepsilon K_{2} K
\end{aligned}
$$

$m \rightarrow \infty$.

THEOREM 5.4. Suppose: (1) $G(t)$ and $E(s)$ are defined by (1.2) and $\left\{a_{k}\right\} \in C(2)$.

(2) $f(x)=\int_{-\infty}^{\infty} G(x-t) \varphi(t) d t$

(3) For some $K$ and $M|\varphi(X)| \leqq K e^{M|t|}$ where $M=\min \left|\operatorname{Re} a_{k}\right|$.

(4) $S_{2 m}^{\beta / 2} \leqq K Q_{m}^{1 / 4}$ for some $\beta \geqq 1$.

(5) $\varphi(x)-\varphi(t)=o\left(|t-x|^{\beta-1}\right) t \rightarrow x$. 


$$
\lim _{m \rightarrow \infty} P_{2 m}(D) f(x)=\varphi(x)
$$

\section{Proof. Similar to that of Theorem 5.3.}

REMARK. When $\beta$ of condition (4) of Theorem 5.4 and Theorem 5.3 is equal to one, the condition on $\varphi(t)$ is mere continuity at a point $t=x$.

Lemma 5.5. If an integer $r$ exists such that for all $n\left|a_{n+r}\right|>$ $q\left|a_{n}\right|$ for $q>1$, then

$$
\left(\sum_{k=m+1}^{\infty}\left|a_{k}\right|^{-1-\grave{\delta}}\right)^{1 / 1+\delta} \leqq K Q_{m}^{1 / 4} \quad 0 \leqq \delta \leqq 1
$$

( for $\delta=1$ we have $\left.S_{2 m}^{1 / 2} \leqq K Q_{m}^{1 / 4}\right)$.

Proof. Obvious.

CoROLlary 5.5. If the kernel is defined by $a_{2 k}=2^{k-1}(1+i)$ and $a_{2 k-1}=-2^{k-1}(1+i)$ then (5.3) is valid at any point of continuity.

6. Examples, remarks and generalizations. In this section we shall show some examples of convolution transform by giving its related sequence $\left\{a_{k}\right\}$. When we say $G(t) \in A(2), B(2, \delta)$ or $C(2)$ we mean that there is an order for which $\left\{a_{k}\right\} \in A(2), B(2, \delta)$ and $C(2)$ respectively.

EXAMPLE 6.1. $\left\{a_{k}\right\}$ defined by $a_{2 k-1}=k, a_{2 k}=q^{k} e^{i \theta_{k}}$ for $q>1$, $0<\delta<\pi(1 / 2),\left|\theta_{k}-(\pi / 2)\right|>\delta,\left|\theta_{k}+(\pi / 2)\right|>\delta . \quad\left\{a_{k}\right\} \in A(2)$. The kernel $G(t)$ related to $\left\{a_{k}\right\}$ is not necessarily one of those discussed in [6]; for instance in case $\theta_{k}=(2 / 5) \pi$ the result of Theorem 5.2 can be applied as $S_{2 m}^{(j)} \geqq L(j) S_{2 m}$ for all $j(j=2$ is needed).

EXAMPLE 6.2. $G(t)$ defined by $a_{2 k-1}=(2 k-1) ! a_{2 k}=(2 k) ! e^{i \theta_{k}}$ where $-\pi<\theta_{k}<\pi,\left|\theta_{k}-(\pi / 2)\right|>\delta,\left|\theta_{k}+(\pi / 2)\right|>\delta$ for some $0<$ $\hat{\delta}<\pi / 2$ where the $a_{k}$ 's are arranged in the order of $\left|a_{k}\right|$. Theorem 5.2 does not apply here as one can easily verify that $S_{2 m}^{(j)}=o\left(S_{2 m}\right)$ $m \rightarrow \infty$ for all $j>0$. We can apply Theorem 5.1 and get an inversion formula.

EXAMPLE 6.3. Let $c_{k}$ be real, $\sum c_{k}^{-2}<\infty$ and

$$
a_{2 k-1}=c_{k}\left(\sin \theta_{1}\right)^{-1} e^{i \theta_{2}}, \quad a_{2 k}=c_{k}\left(\sin \theta_{2}\right)^{-1} e^{-i \theta_{1}}
$$

where $0<\theta_{1}, \theta_{2}<\pi / 2,0<\delta_{1}<\theta_{1}+\theta_{2}<\pi / 2-\delta_{2}$. (1.5) is easily veri- 
fied. (1.6) is valid also since $\sin ^{2} \theta_{1}+\sin ^{2} \theta_{2}-4 \sin ^{2} \theta_{1} \sin ^{2} \theta_{2} \geqq \eta$ and $\cos ^{2} \theta_{1}>\sin ^{2} \theta_{2}$ and therefore $\sin ^{2} \theta_{1}+\sin ^{2} \theta_{2}<1$ implies

$$
\left(1-\frac{\eta}{2}\right)\left(\sin ^{2} \theta_{1}+\sin ^{2} \theta_{2}\right)-4 \sin ^{2} \theta_{1} \sin ^{2} \theta_{2} \geqq \frac{\eta}{2} \text {. }
$$

Using $\sin ^{2} \theta_{1}<\cos ^{2} \theta_{2}$ and $\sin ^{2} \theta_{2}<\cos ^{2} \theta_{1}$ we get after some calculations that $\sin ^{2}\left(\theta_{1}+\theta_{2}\right) \sin ^{2}\left(\theta_{1}-\theta_{2}\right)<\sin ^{2} \theta_{1}+\sin ^{2} \theta_{2}-4 \sin ^{2} \theta_{1} \sin ^{2} \theta_{2} \quad$ which implies (1.7). It should be noted that the class defined by $a_{2 k-1}=a_{2 k}$ and $\min \left(\left|\arg a_{2 k}\right|\left|\arg -a_{2 k}\right|\right) \leqq \pi / 4-\delta$ which includes Garder's class of transforms [5] as a very special case, is a special case of this example. Theorem 5.2 can be applied here.

EXAMPLE 6.4. Let $c_{k}$ be real, $\sum c_{k}^{-2}<\infty$ and $a_{2 k-1}=c_{k}\left(\sin \theta_{1}\right)^{-1} e^{i \theta_{2}}$. $a_{2 k}=-c_{k}\left(\sin \theta_{2}\right)^{-1} e^{i \theta_{1}}$ where either $0<\theta_{1}, \theta_{2}<\pi / 2,0<\delta,<\theta_{1}+\theta_{2}<\pi / 2-\delta_{2}$ or $-(\pi / 2)<\theta_{1}, \theta_{2}<0,-(\pi / 2)+\delta_{2}<\theta_{1}+\theta_{2}<\delta_{1}<0$.

The inqualities used in Example 6.3 for the validity of $\left\{a_{k}\right\} \in A(2)$ can also be used here. It should be noted that the class of transforms defined by Dauns and Widder [1] is the case $\theta_{1}=\theta_{2}$ here.

EXAMPLE 6.5. Let $a_{2 n-1}=n^{\gamma}(1+i), a_{2 n}=n^{\gamma}(1-i), \gamma>1 / 2 . \quad$ In this case $\left\{a_{k}\right\} \notin A(2)$ (since (1.6) is not satisfied) but clearly $\left\{a_{k}\right\} \in C(2)$. In this case $\beta$ of Theorem 5.4 is easily computed as $S_{2 m}=$ $(1+o(1)) 4 \gamma m^{-2 \gamma+1}, Q_{m}=(1+o(1)) 4 \gamma m^{-4 \gamma-1} m \rightarrow \infty$ and therefore

$$
\left(-\gamma+\frac{1}{2}\right) \beta \leqq-\gamma+\frac{1}{4}
$$

that is $\beta \geqq 1+1 / 2(2 \gamma-1)$. From this one can see easily that: (a) When $\gamma=1$ it is enough to have at $t=x \varphi(t)-\varphi(x)=o\left(|t-x|^{1 / 2}\right)$ for Theorem 5.4.

(b) When $\gamma>3 / 4$ it is enough to have $\varphi(t)-\varphi(x)=0(t-x)$ $t \rightarrow x$ or it is enough for $\varphi(t)$ to have a left and right derivative at $t=x$.

EXAMPLE 6.6. $\quad a_{2 n-1}=n^{\gamma}(1+i), a_{2 n}=-n^{\gamma}(1+i) . \quad$ For $\quad \gamma>3 / 4$ $\left\{a_{k}\right\} \in B(2,1 / 3)$. The following remarks will constitute generalizations of the Theorems of $\S 5$ in various directions.

REMARK 6.1. In Theorem $5.1|\varphi(t)| \leqq K e^{1 /|t|}$ can be replaced by $\left|\int_{0}^{t} \varphi(t) d t\right| \leqq K e^{M|t|}$ if for every $\delta>0$ if

$$
\left(S_{2 m} S_{2 m}^{(1)} S_{2 m}^{(2)}\right)^{-1 / 2} \exp \left(-\delta S_{m}^{-1 / 2}\right)=o(1) \quad m \rightarrow \infty .
$$

This result can be achieved by a proper change of Theorem 4.2 that will yield now 


$$
\left|G_{2 m}^{\prime}(t)\right| \leqq M\left(S_{2 m} S_{2 m}^{(1)} S_{2 m}^{(2)}\right)^{-1 / 2} \exp \left(-A S_{2 m}^{-1 / 2}|t|\right)
$$

REMARK 6.2. In Theorems 5.3 and 5.4 condition (3) can be replaced by $\left|\int_{0}^{t} \varphi(t) d t\right| \leqq K e^{M|t|}$ if either $Q_{m}^{(1)} \geqq L Q_{m}$ or if for all $\eta>0$

$$
\left.\left(Q_{m}^{(1)} Q_{m}\right)^{-1 / 4} \exp \left(-\eta \sum_{m+1}^{\infty}\left|a_{k}\right|^{-1-\delta}\right)^{-1 /(1+\delta)}\right)=o(1) \quad m \rightarrow \infty
$$

for Theorem 5.3 and $\left(Q_{m}^{(1)} Q_{m}\right)^{-1 / 4} \exp \left(-\eta S_{2 m}^{-1 / 2}\right)=o(1) m \rightarrow \infty$ for Theorem 5.4. For the above generalization slight improvements of Theorems 4.6 and 4.7 are needed in case $Q_{m}^{(1)} \geqq L Q_{m}$ is not satisfied.

REMARK 6.3. If $S_{2 m}^{-1 / 2} \leqq K Q_{m}^{1 / 4}$, then in Theorem $5.4 \varphi(t)-\varphi(x)=$ 0 (1) $t \rightarrow x$ can be replaced by

$$
\int_{x}^{x+h}[\varphi(t)-\varphi(x)] d t=o(h) \quad h \rightarrow 0 .
$$

REMARK 6.4. If in Theorem 5.3 (5) is replaced by

$$
\varphi(t)-\varphi(x+)=o\left(|t-x|^{\beta-1}\right) \quad t \rightarrow x+
$$

and

$$
\varphi(t)-\varphi(x-)=o\left(|t-x|^{\beta-1}\right) \quad t \rightarrow x-,
$$

then

$$
\lim _{m \rightarrow \infty} P_{2 m}(D) f(x)=\frac{1}{2}[\varphi(x+)+\varphi(x-)] .
$$

REMARK 6.5. If in Theorem 5.3 we have

$$
\left(\sum_{m+1}\left|a_{k}\right|^{-1-\hat{o}}\right)^{1 / 1+\hat{o}} \leqq K_{1} Q_{m},
$$

then $\varphi(t)-\varphi(x)=o(1) t \rightarrow x$ can be replaced by

$$
\int_{x}^{x+h}[\varphi(x \pm t)-\varphi(x \pm 0) d t=o(h) \quad h \rightarrow 0+
$$

and then

$$
\lim _{m \rightarrow \infty} P_{2 m}(D) f(x)=\frac{1}{2}[\varphi(x+0)+\varphi(x-0)] .
$$




\section{REFERENCES}

1. J. Dauns and D. V. Widder, Convolution transforms whose inversion function have complex roots, Pacific J. Math. (2) 15 (1965), 427-442.

2. Z. Ditzian, Inversion formulae and various properties of integral transforms, $\mathrm{Ph}$.

D. thesis, 1965, Hebrew University, Jerusalem, Israel (Hebrew, English summary).

3. - On asymptotic estimates for kernels of convolution transforms, Pacific J. Math. 21 (1967), 249-254.

4. Z. Ditzian and A. Jakimovski, Inversion and jump formulae for variation diminishing transforms. (to appear)

5. A. O. Garder, The inversion of a special class of convolution transforms M. A. thesis, 1950, Washington University, St. Louis Missouri.

6. I. I. Hirschman and D. V. Widder, Convolution transforms with complex kernels, Pacific J. Math. 1 (1951).

7. - The Convolution Transform, Princeton Press, 1955.

8. R. M. Mcleod, Mean value theorems for vector valued functions, Proc. Edin. Math. Soc. (11), 14 (1965) Part 3, 197-211.

9. D. V. Widder, The Laplace Transform, 2nd ed., Princeton Press. 1946.

Received December 20, 1966.

The University of Alberta

Edmonton, Canada 



\section{PACIFIC JOURNAL OF MATHEMATICS}

\section{EDITORS}

H. ROYDEN

Stanford University

Stanford, California

\section{J. P. Jans}

University of Washington

Seattle, Washington 98105

\section{J. DUGUNDJI}

Department of Mathematics University of Southern California Los Angeles, California 90007

\section{RICHARD ARENS}

University of California

Los Angeles, California 90024

\section{ASSOCIATE EDITORS}

E. F. BECKENBACH

B. H. NEUManN

F. WOLF

K. YosIDA

\section{SUPPORTING INSTITUTIONS}

UNIVERSITY OF BRITISH COLUMBIA CALIFORNIA INSTITUTE OF TECHNOLOGY UNIVERSITY OF CALIFORNIA MONTANA STATE UNIVERSITY UNIVERSITY OF NEVADA NEW MEXICO STATE UNIVERSITY OREGON STATE UNIVERSITY UNIVERSITY OF OREGON OSAKA UNIVERSITY UNIVERSITY OF SOUTHERN CALIFORNIA
STANFORD UNIVERSITY

UNIVERSITY OF TOKYO UNIVERSITY OF UTAH WASHINGTON STATE UNIVERSITY UNIVERSITY OF WASHINGTON AMERICAN MATHEMATICAL SOCIETY CHEVRON RESEARCH CORPORATION TRW SYSTEMS NAVAL WEAPONS CENTER 


\section{Pacific Journal of Mathematics}

\section{Vol. 25, No. $1 \quad$ September, 1968}

Glen Eugene Bredon, Cosheaves and homology................... 1

Robin Ward Chaney, A chain rule for the transformation of integrals in

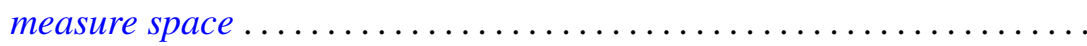

Colin W. Clark, On relatively bounded perturbations of ordinary differential operators................................... 59

John Edwin Diem, A radical for lattice-ordered rings.............. 71

Zeev Ditzian, On a class of convolution transforms ................ 83

Dennis Garoutte and Paul Adrian Nickel, A note on extremal properties characterizing weakly $\lambda$-valent principal functions............. 109

Shwu-Yeng Tzeng Lin, Fixed point properties and inverse limit spaces . . . 117

John S. Lowndes, Some dual series equations involving Laguerre polynomials ................................. 123

Kirti K. Oberai, Sum and product of commuting spectral operators ....... 129

J. N. Pandey and Armen H. Zemanian, Complex inversion for the generalized convolution transformation..................... 147

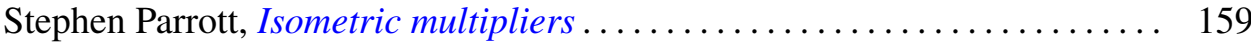

Manoranjan Prasad, Note on an extreme form .................. 167

Maciej Skwarczyński, A representation of a bounded function as infinite product in a domain with Bergman-Shilov boundary surface ......... 177

John C. Taylor, The Šilov boundary for a lattice-ordered semigroup ...... 185 Donald Reginald Traylor and James Newton Younglove, On normality and pointwise paracompactness ............................. 193

L. Tzafriri, Quasi-similarity for spectral operators on Banach spaces ... 